\title{
Validating the turbulence parameterization schemes of a numerical model using eddy dissipation rate and turbulent kinetic energy measurements in terrain-disrupted airflow
}

\author{
P. W. Chan
}

Received: 19 June 2009/ Accepted: 28 September 2010/Published online: 9 October 2010

(C) The Author(s) 2010. This article is published with open access at Springerlink.com

\begin{abstract}
A number of turbulence parameterization schemes are available in the latest version (6.0) of the Regional Atmospheric Modelling System (RAMS). Chan in Meteorol Atmos Phys 103:145-157, (2009), studied the performance of these schemes by simulating the eddy dissipation rate (EDR) distribution in the vicinity of the Hong Kong International Airport (HKIA) and comparing with the EDR measurements of remote-sensing instruments at the airport. For the e-l (turbulent kinetic energy - mixing length) scheme considered in that study, the asymptotic mixing length was assumed to be a constant. This assumption is changed in the present paper, a variable asymptotic mixing length is chosen and simulations of EDR fields are repeated for terrain-disrupted airflow in the vicinity of HKIA. It is found that, with a variable asymptotic mixing length, the performance of the e-l scheme is greatly improved. With suitable choice of the empirical constants in the turbulence closure, the accuracy of the EDR profile (in comparison with LIDAR and wind profiler measurements) is found to be comparable with that predicted by the Deardorff scheme. A study on the sensitivity of the simulation results to these empirical constants has also been performed. Moreover, as a follow-up of the previous study of Chan in Meteorol Atmos Phys 103:145-157, (2009), case studies have been conducted on the following issues of the model simulation of turbulence for aviation application: (a) the effect of vertical gridding on the simulation results, (b) possibility of false alarm (such as over-forecasting of EDR value) in light turbulence cases, and (c) the performance in the simulation of other turbulence intensity metric for aviation purpose, e.g. TKE.
\end{abstract}

P. W. Chan $(\bowtie)$

Hong Kong Observatory, Hong Kong, China

e-mail: pwchan@hko.gov.hk

\section{Introduction}

The Hong Kong International Airport (HKIA) is situated in the vicinity of a complex terrain. To its south is the mountainous Lantau Island with peaks rising to about $1 \mathrm{~km}$ above mean sea level (AMSL) and valleys as low as $400 \mathrm{~m}$ in between. The airport is surrounded by sea in the west, north and east. To its northeast, at a distance of $10-12 \mathrm{~km}$, there are a couple of mountains with a height of 500-600 m. Airflow disturbances arising from terrain disruption may bring about significant turbulence to aircraft landing at or departing from HKIA. Following the requirement of the International Civil Aviation Organization (ICAO), the turbulence intensity in aviation is quantified in terms of the cube root of eddy dissipation rate (EDR), $\varepsilon$. Forecasting of $\mathrm{EDR}^{1 / 3}$ by numerical weather prediction (NWP) models would be useful in the provision of turbulence alerting services to aircraft.

Chan (2009) demonstrated that the forecasting of $\mathrm{EDR}^{1 / 3}$ in typical cases of terrain-disrupted airflow around HKIA was possible by running the Regional Atmospheric Modelling System (RAMS) (Cotton et al. 2003) version 6.0 at high spatial resolution. The innermost model domain had a horizontal resolution of $50-200 \mathrm{~m}$. The forecasting results had been shown to depend very much on the choice of the turbulence parameterization scheme. It turned out that the Deardorff scheme appeared to have the best performance in the selected cases. In RAMS 6.0, there were also a couple of new turbulence parameterization schemes available, such as the e-l [turbulent kinetic energy (TKE) - mixing length] scheme of Trini Castelli et al. (2005). However, this scheme was found to give too much turbulence near the ground and $\mathrm{EDR}^{1 / 3}$ dropped too rapidly with altitude in comparison with the other turbulence schemes and actual measurements. 
For the e-1 scheme implemented in RAMS 6.0, the mixing length $l$ is parameterized following the Blackadar formulation (details could be found in Trini Castelli et al. 2001):

$l=\frac{k z}{1+k z / l_{\infty}}$

where $k$ is the von Karman constant (0.4) and $z$ is the height. The value of $l_{\infty}$ has to be assigned by the user of the model. A constant asymptotic mixing length $l_{\infty}$ may be adopted for e-1 scheme. Such choice was made in Chan (2009), where a constant value available for $l_{\infty}$ in RAMS configuration file and related to neutral boundary layer conditions was used. Since this value may not be applicable for the meteorological conditions under consideration, in the present study an alternative option available in RAMS, that is using a variable asymptotic mixing length is applied to three different kinds of weather condition over southern China, namely, southwest monsoon in an unstable boundary layer in the summer, northeast monsoon in a stable boundary layer in the winter and spring, and east to southeasterly winds associated with a tropical cyclone. In the variable asymptotic mixing length formulation, $l_{\infty}$ is determined following Mellor and Yamada (1982), that is:

$l_{\infty}=a_{\infty} \frac{\int z \sqrt{E} \mathrm{~d} z}{\int \sqrt{E} \mathrm{~d} z}$

where $a_{\infty}$ is taken to be 0.1 and $E$ is the turbulent kinetic energy.
Moreover, in Chan (2009), a number of issues about simulation of turbulence intensity $\left(\mathrm{EDR}^{1 / 3}\right)$ at a high spatial resolution (horizontal resolution of at least several hundred metres) have been pointed out, including:

(a) The effect of vertical gridding;

(b) Possibility of false alarm, namely, whether the model simulation would give larger $\mathrm{EDR}^{1 / 3}$ than actual measurements, especially in light turbulence situation; and

(c) Performance of model simulation in forecasting other metrics of turbulence intensity for aviation application, e.g. TKE.

The above issues would also be examined in this paper based on case studies.

\section{Meteorological equipment}

The meteorological equipment considered in this study is shown in Fig. 1. They are part of the suite of meteorological instruments used by the Hong Kong Observatory (HKO) in the monitoring of weather conditions in the vicinity of HKIA.

The EDR profiles used in this paper mainly come from the radar wind profilers. With an operating frequency of $1,299 \mathrm{MHz}$, the wind profiler emits three radio beams (one vertical and two oblique) into the atmosphere to measure the three components of the wind within the boundary
Fig. 1 The geographical setup in the vicinity of the Hong Kong International Airport (HKIA) with height contours in $100 \mathrm{~m}$. The locations of the meteorological equipment considered in the present study are also shown

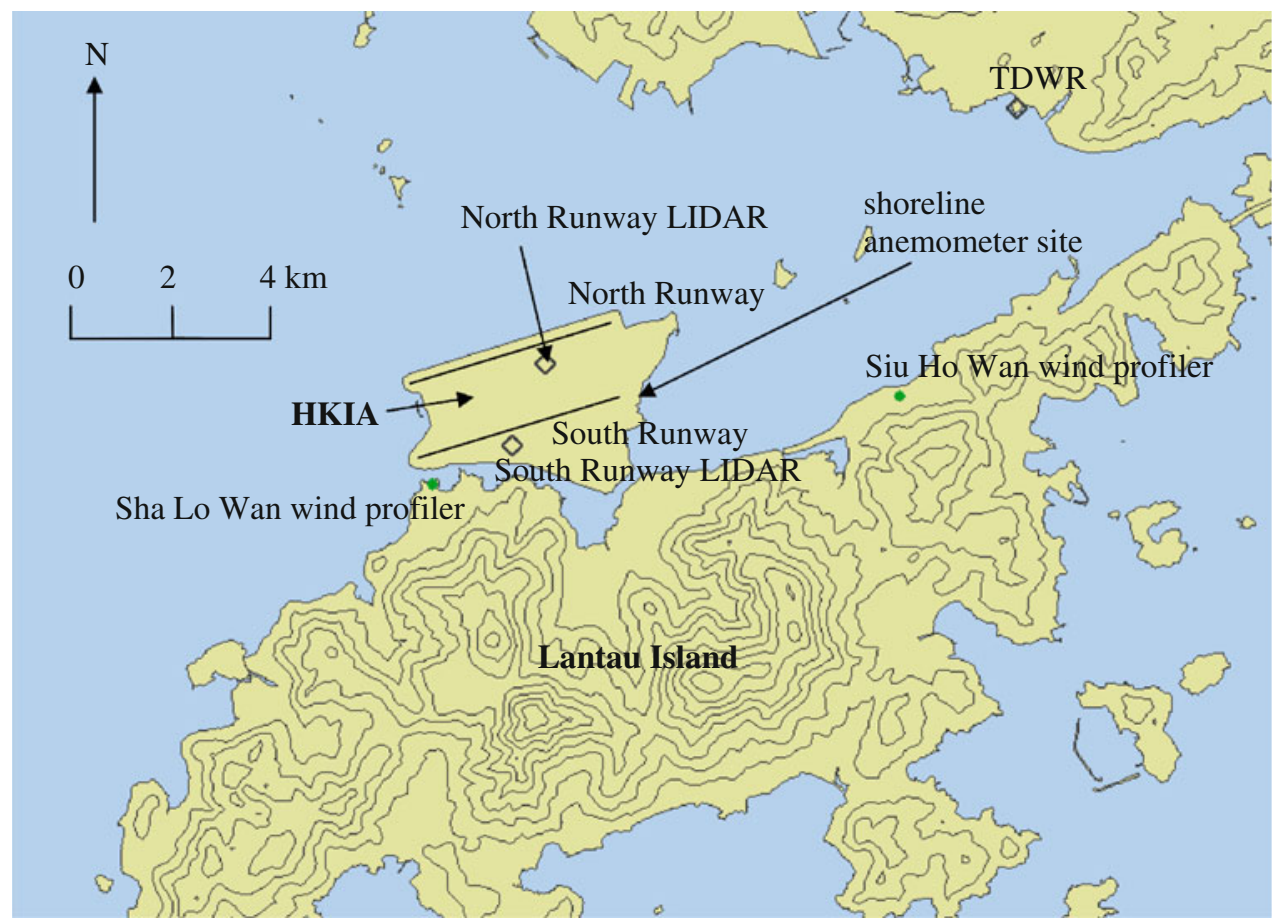


layer. The spectral width of the returned radio signal is related to turbulence:

$\sigma_{\mathrm{t}}^{2}=\sigma_{\mathrm{s}}^{2}+\sigma_{\mathrm{a}}^{2}+\sigma_{11}^{2}$

where $\sigma_{\mathrm{t}}^{2}$ is the total velocity variance measured in the Doppler spectral peak, $\sigma_{\mathrm{s}}^{2}$ is the contribution from wind shear across the radar beam, $\sigma_{\mathrm{a}}^{2}$ is a contribution depending on antenna properties (which is significant only for scanning radars but not for wind profilers), and $\sigma_{11}^{2}$ is the radial velocity variance (the turbulence term) which is the main interest of this study. The spectral width is determined using the NCAR Improved Moments Algorithm (NIMA) by removing artificial spectral peaks due to clutters and radio interference (Morse et al. 2002). The same EDR profiles from the radar wind profilers have been used in the previous study (Chan 2009). The wind profilers are located at Sha Lo Wan (SLW) and Siu Ho Wan (SHW), each monitoring either side (west or east) of the flight paths of the aircraft. Their locations are shown in Fig. 1. Please note that EDR is not determined from the variance of the velocity measured by the radar wind profiler. It is based on the spectrum width of the atmospheric return signal as measured by the profiler.

Radar wind profilers only measure the vertical wind and turbulence profiles above their antennae. To give an overview of the wind patterns around HKIA arising from airflow disruption by complex terrain, two other types of remote-sensing equipment have also been used by HKO. For non-rainy weather condition, the Doppler light detection and ranging (LIDAR) systems are used to give the line-of-sight velocities up to a distance of $10 \mathrm{~km}$ away. Two LIDARs have been installed at HKIA (locations in Fig. 1), with each LIDAR monitoring a particular runway of the airport. They are identical and use infrared laser beam with a wavelength of about $2 \mu \mathrm{m}$ to track the motion of aerosols in the air blown along with the winds. The range resolution is about $100 \mathrm{~m}$ and the accuracy of Doppler velocity measurement is within $1 \mathrm{~m} / \mathrm{s}$. Further technical details about the LIDAR systems could be found in Shun and Chan (2007).

The measurement range of LIDAR would be very much limited in rain or very humid weather due to attenuation of laser beams in suspending/falling water droplets. In such situations, the wind patterns around HKIA would be monitored by a terminal Doppler weather radar (TDWR) to the northeast of the airport (location in Fig. 1). This is a C-band microwave radar to measure the line-of-sight velocity by tracking the motion of water droplets in the air blown along with the wind. The range is about $90 \mathrm{~km}$ and the radial resolution is about $250 \mathrm{~m}$. The lowest elevation scan, namely, elevation angle of $0.6^{\circ}$ from horizon, is mostly used for detecting microburst and giving an overview of the wind situation inside and around HKIA. Further technical details of the TDWR could be found in Shun and Johnson (1995).

In order to assess the performance of numerical model in the simulation of other turbulence intensity metric for aviation application (such as TKE), the minisodar at shoreline anemometer site (location in Fig. 1) has also been considered in the present paper. The sodar emits acoustic waves with a frequency of $4.5 \mathrm{kHz}$. The measurement range is configured to be $200 \mathrm{~m}$ with a vertical resolution of $5 \mathrm{~m}$ starting from about $20 \mathrm{~m}$ above ground. Vertical profiles of the three components of the wind and TKE are available every $1 \mathrm{~min}$. In the present paper, only the TKE profile would be considered.

\section{Turbulence parameterization schemes and numerical model setup}

In e-1 scheme, the diffusion coefficient of momentum $K_{\mathrm{m}}$ is determined as:

$K_{\mathrm{m}}=c_{\mu} \mathrm{e}^{1 / 2} l$

where $c_{\mu}$ is a closure empirical constant. Following $\mathrm{Xu}$ and Taylor (1997), it has a value of 0.41. This constant is in turn related to the corresponding empirical constant of dissipation term of TKE $\varepsilon_{\mu}=c_{\mu}^{3}$. In the present study, $c_{\mu}$ is made variable between 0.1 and 0.7 and the resulting $\mathrm{EDR}^{1 / 3}$ field is compared with the actual measurements (mainly vertical EDR profiles from the two radar wind profilers near HKIA) to find out a suitable value for this empirical constant.

To find out the performance of e-1 scheme, simulations have also been made using the more conventional schemes available in RAMS, namely, Mellor-Yamada 2.5 scheme (Mellor and Yamada 1982) and Deardorff scheme (1980). Same turbulence parameterization schemes have been considered in the previous study (Chan 2009).

The model setup is similar to that in Chan (2009). The initial and boundary conditions for RAMS are obtained from a meso-scale operational regional spectral model (ORSM) of HKO. ORSM is a hydrostatic model with a horizontal resolution of $20 \mathrm{~km}$. Sigma-p hybrid vertical co-ordinates are used with a model top of $10 \mathrm{hPa}$. There are 40 model levels in the vertical. Planetary boundary layer is handled in such a way that non-local specification of turbulent diffusion and counter-gradient transport in unstable boundary layer are considered. In case of rain, three-dimensional multivariate optimal interpolation is performed. The heating rate of the precipitation process is adjusted to correspond to the rainfall amount observed.

Only three nested domains are employed in the present study of RAMS, namely, at spatial resolutions of $4 \mathrm{~km}$, 
$800 \mathrm{~m}$ and $200 \mathrm{~m}$. In the second and third domains, terrain data of Hong Kong at $100 \mathrm{~m}$ horizontal resolution is used in order to resolve the major topographical features around HKIA. The domains of the simulation for grids 1 and 2 could be found in Fig. 2a, and that for grid 3 could be found in Fig. 3b. The ratio of 5 for horizontal resolution from grid 1 to grid 2, though a bit large, may be justified in view of the reasonable simulation results as obtained in Chan (2009) and only terrain of a larger scale is considered in the first two grids. The vertical gridding is shown in Fig. 2b. It starts off with a size of $20 \mathrm{~m}$ and a stretching ratio of 1.15 is used until the vertical grid reaches a size of $1,200 \mathrm{~m}$. There are 32 grid points in the vertical for the innermost domain (grid 3), which reaches a height of more than $15 \mathrm{~km}$. As in Chan (2009), Mellor-Yamada turbulence scheme is used in grids 1 and 2 . The turbulence scheme in grid 3 is varied, namely, selecting among Mellor-Yamada scheme, Deardorff scheme and e-1 scheme. In the comparison with actual observations as discussed in the sections below, only the results of grid 3 are considered.

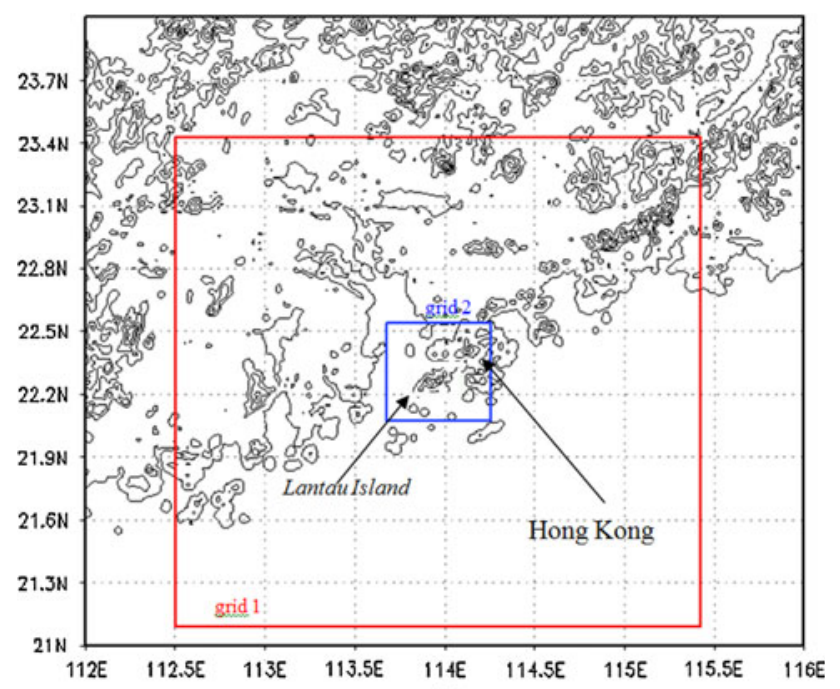

(a)

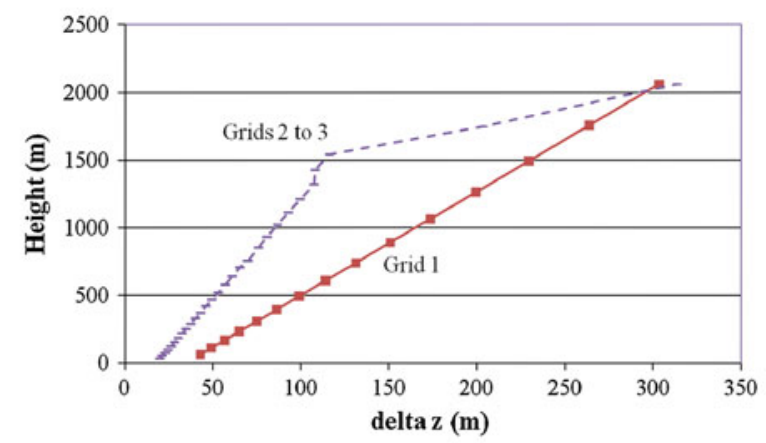

(b)

Fig. 2 a Domains of simulation for grids 1 and 2; and b vertical gridding of grids $1-3$

\section{Summer monsoon case}

A moderate southwest monsoon case on 1 July 2008 is studied. This is a typical situation of south to southwesterly flow over southern China in the summer time. The LIDAR measurements around HKIA at the time of interest (01:20 UTC on that day) are shown in Fig. 3a. It could be seen that the wind pattern around HKIA is not uniform. In the broadly southerly flow, there are streaks of higher and lower wind speeds coming out from Lantau Island. These streaks probably arise from the disruption of the southerly flow by the complex terrain (Chan 2007).

The numerical simulation starts at 00 UTC, 1 July 2008. The results at 01:20 UTC on that day are considered here. The model-simulated wind field using the e-l scheme with $c_{\mu}=0.4$ is shown in Fig. $3 \mathrm{~b}$. The horizontal wind vector has been resolved and coloured with respect to the line-ofsight directions of one of the LIDAR systems for direct comparison with the actual observations (Fig. 3a). It could be seen that, apart from a slightly easterly component of the wind field (which comes from the outer meso-scale model), the general pattern of Doppler velocity is consistent with the LIDAR measurements. Velocity streaks show up in the simulation results as well. The successful capturing of such features is believed to result partly from the input of complex terrain around HKIA in high spatial resolution and the reasonable treatment of the sub-grid scale turbulence.

The turbulence intensity $\left(\mathrm{EDR}^{1 / 3}\right)$ field from the model simulation is given in Fig. 3c. More turbulent flow (coloured light blue in Fig. 3c) extends up to 5-6 km downstream of Lantau Island. The turbulence is particularly strong just close to the downstream side of Lantau terrain. The overall turbulence pattern appears to be reasonable considering the mechanical generation of turbulence as the airflow impinges on the complex terrain.

The model-simulated EDR ${ }^{1 / 3}$ profiles at SLW and SHW are qualitatively compared with the actual measurements by radar wind profilers in Fig. 4a, b. The comparison results are better for SLW than for SHW. For SLW, among the e-1 scheme and Deardorff scheme, the model results generally captures the gradual decrease of $\mathrm{EDR}^{1 / 3}$ from the lowest range gate of the profiler (about $120 \mathrm{~m}$ ) up to $1,200 \mathrm{~m}$. On the other hand, Mellor-Yamada scheme overall gives smaller values of $\mathrm{EDR}^{1 / 3}$ in comparison with actual observation. For SHW, once again the simulation results of e-l and Deardorff schemes are better than those of Mellor-Yamada scheme. However, all schemes forecast too rapid drop of $\mathrm{EDR}^{1 / 3}$ above a height of $1,000 \mathrm{~m}$ or so. It is also noted that, for e-l scheme, the optimum value of $c_{\mu}$ reported in the literature (e.g. Xu and Taylor (1997)) is in the region of $0.4-0.5$. As a result, for a too low value (e.g. $c_{\mu}=0.1$ ), the resulting $\mathrm{EDR}^{1 / 3}$ curve deviates 


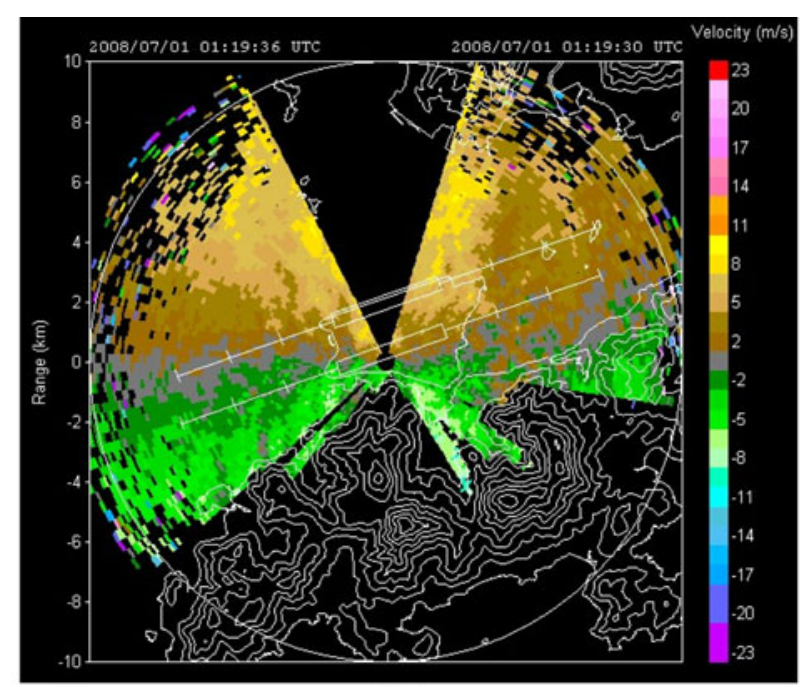

(a)
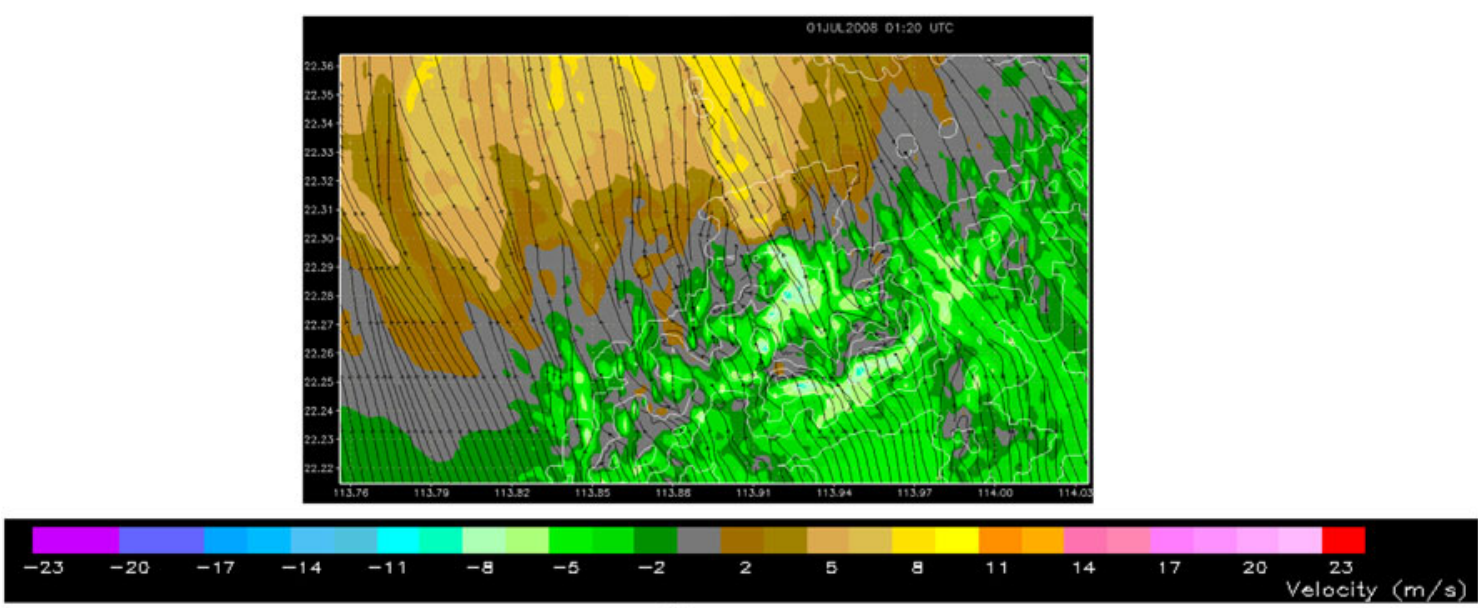

(b)

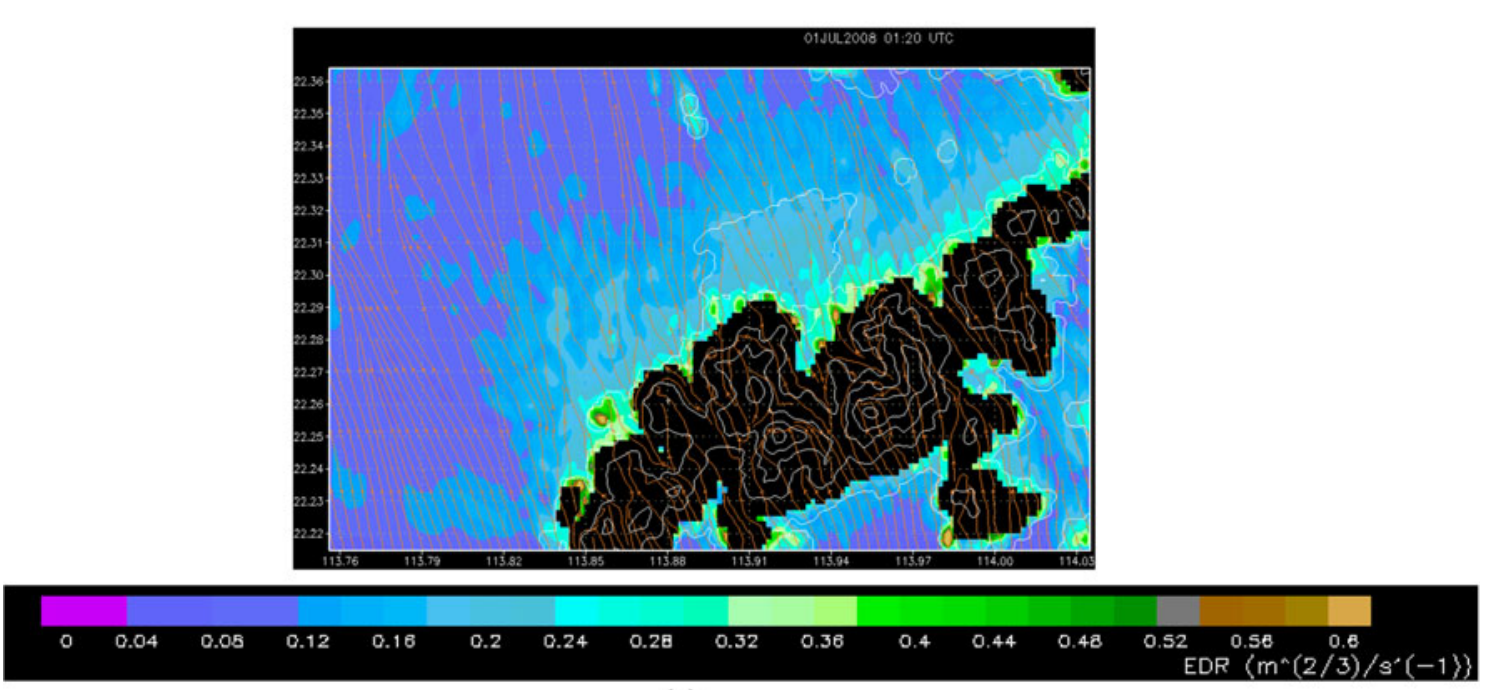

(c)

Fig. 3 The summer monsoon case at 01:20 UTC, 1 July 2008. a Is the velocity imagery from the south runway LIDAR. The modelsimulated winds (resolved along the LIDAR's radials) at a height of
$50 \mathrm{~m}$ are shown in $\mathbf{b}$. The $\mathrm{EDR}^{1 / 3}$ field at the same time from model simulation is given in $\mathbf{c}$ (colour figure online) 


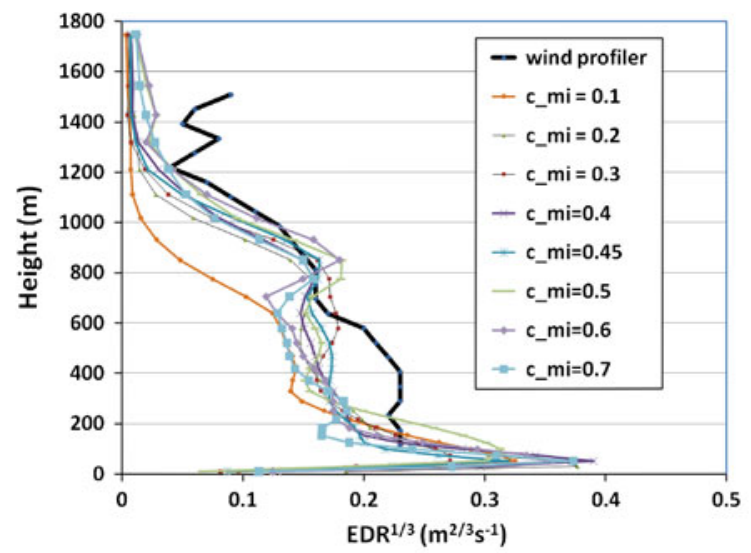

best performing: c_mi $=0.45$

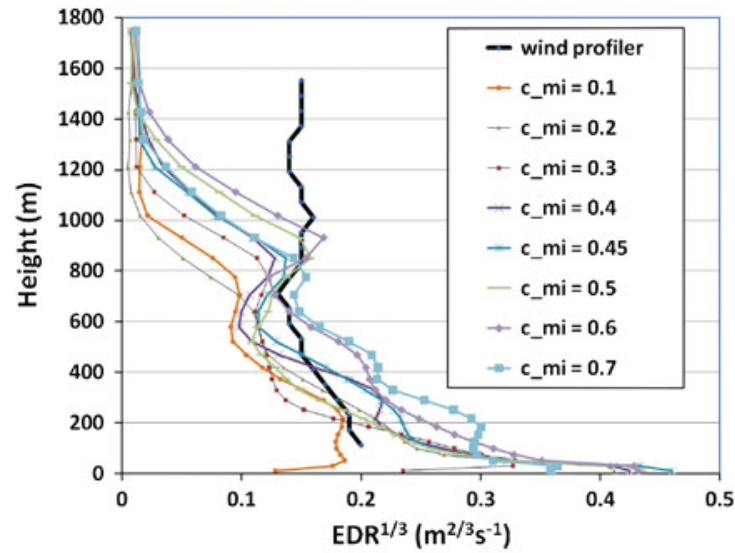

best performing: c_mi $=0.5$

Fig. 4 The $\mathrm{EDR}^{1 / 3}$ profiles from the wind profiler at a Sha Lo Wan and $\mathbf{b}$ Siu Ho Wan in comparison with the model-simulated profiles using the various turbulence parameterization schemes: $c_{-} m i$ the $c_{\mu}$

significantly from the wind profiler measurement. With higher values of $c_{\mu}$, the $\mathrm{EDR}^{1 / 3}$ curves are getting closer to the actual data.

\section{Winter monsoon case}

Moderate easterly winds prevailed along the southern coast of China on 3 December 2008. From the radiosonde ascents at 00 and 12 UTC on that day (not shown), temperature inversion (of a few degrees) or an isothermal was depicted between about 600 and $900 \mathrm{~m}$ above ground. From the LIDAR's velocity imagery (Fig. 5a), easterly flow prevailed in the area of the airport. However, a region of weaker and possibly reverse flow appears to the southwest of HKIA (highlighted in Fig. 5a). The occurrence of such a region is possibly related to the airflow disruption by the complex terrain of Lantau Island in a stable boundary layer. Similar cases have been reported in

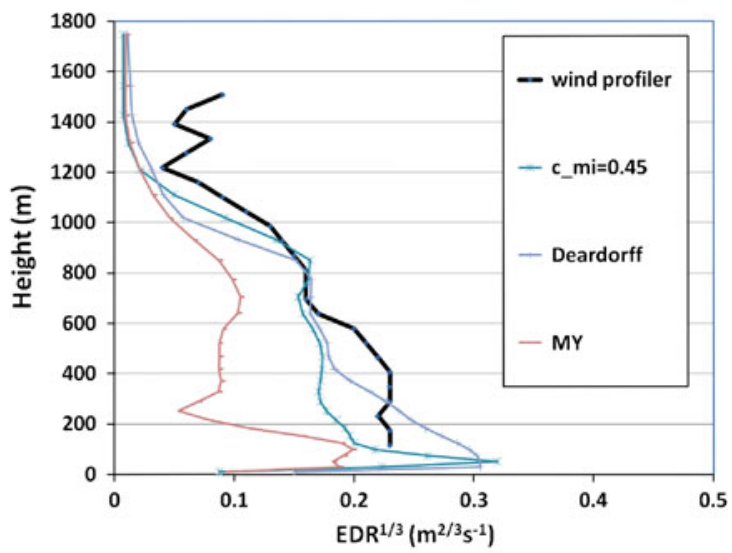

(a)

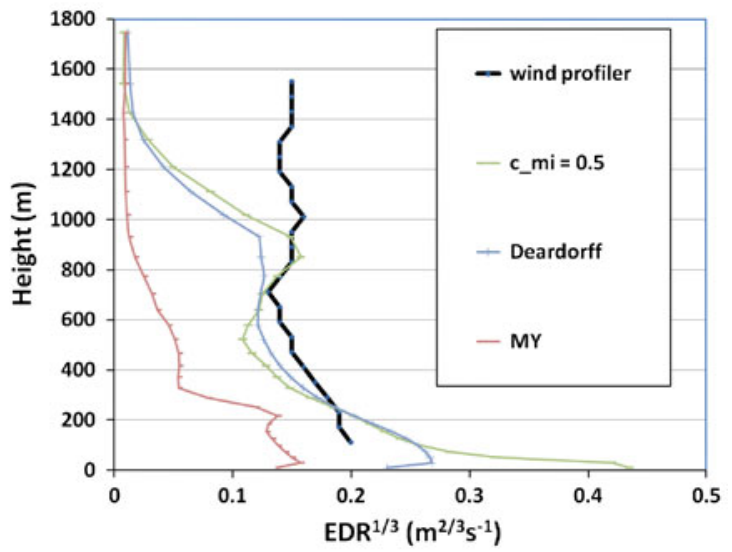

(b)

value in e-1 scheme, Deardorff Deardorff turbulence scheme, $M Y$ the Mellor-Yamada 2.5 scheme available in RAMS 6.0

cross-terrain flow in winter to spring time (Shun and Chan 2007).

The model simulation starts at 00 UTC, 3 December 2008 and the results at 05:30 UTC on that day are analysed here. The model-simulated wind field using the e-l scheme with $c_{\mu}=0.4$ is shown in Fig. $5 \mathrm{~b}$. It could be seen that, apart from the generally easterly flow, there is an area of southerly flow to the west of the HKA. The occurrence of the latter is generally consistent with the Doppler velocity field measured by the LIDAR (Fig. 5a), though the spatial extent of the southerly flow (arising from terrain disruption) may be exaggerated. This feature with RAMS simulation has also been reported in similar case study before (e.g. Chan and Cheung 2009).

The model-simulated $\mathrm{EDR}^{1 / 3}$ field at that time is given in Fig. 5c. More turbulent air is forecast downstream of Lantau Island. Once again, the result appears to be reasonable considering the mechanical generation of turbulence as the airflow impinges on Lantau terrain. 
Fig. 5 Same as Fig. 3 but for

the winter monsoon case at

05:30 UTC, 3 December 2008

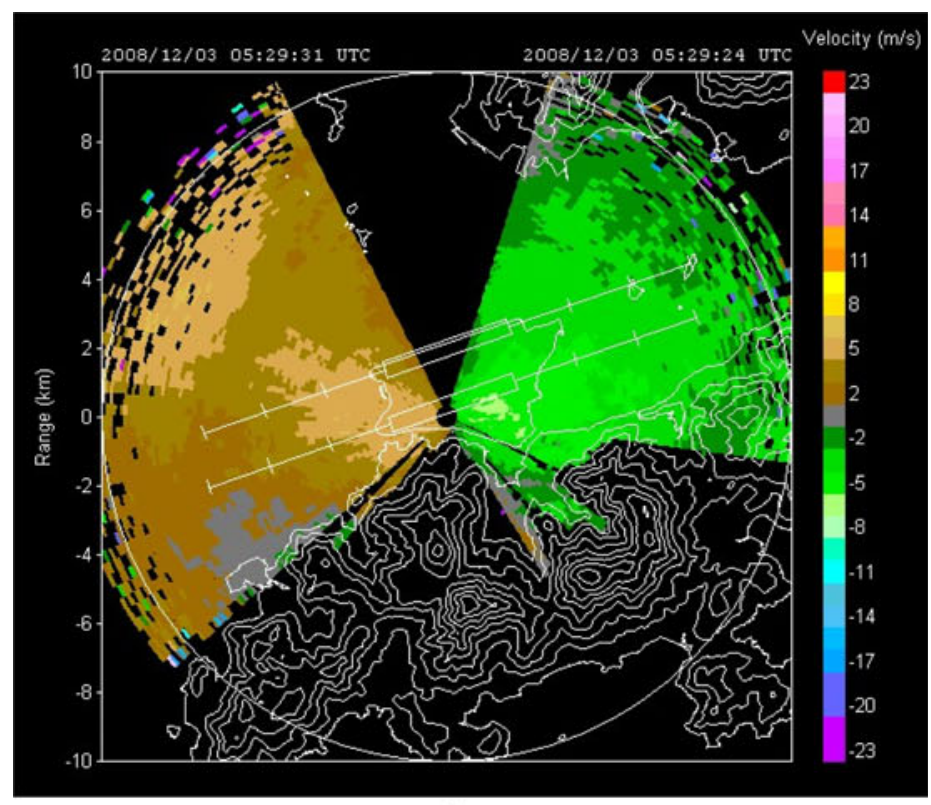

(a)

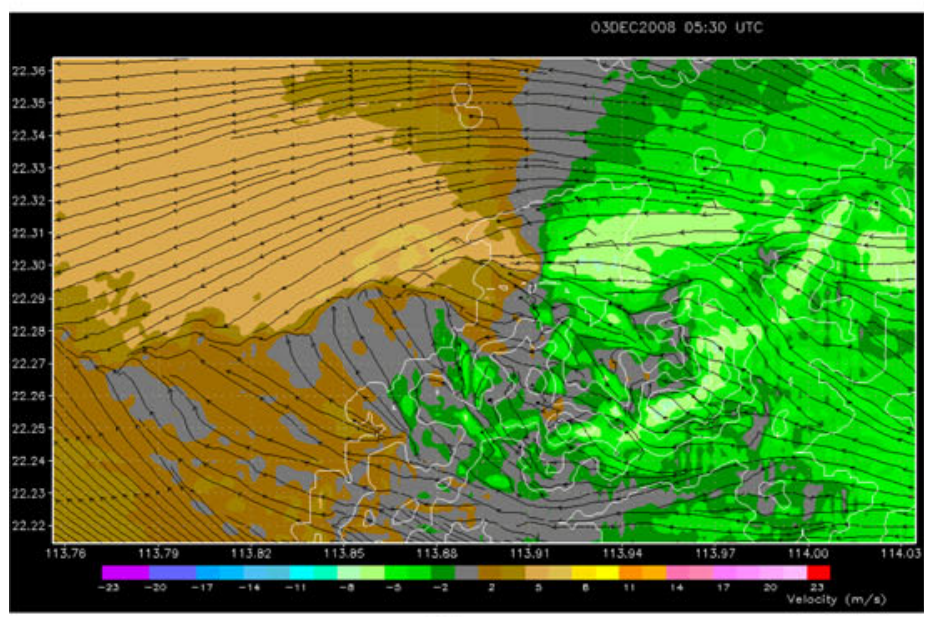

(b)

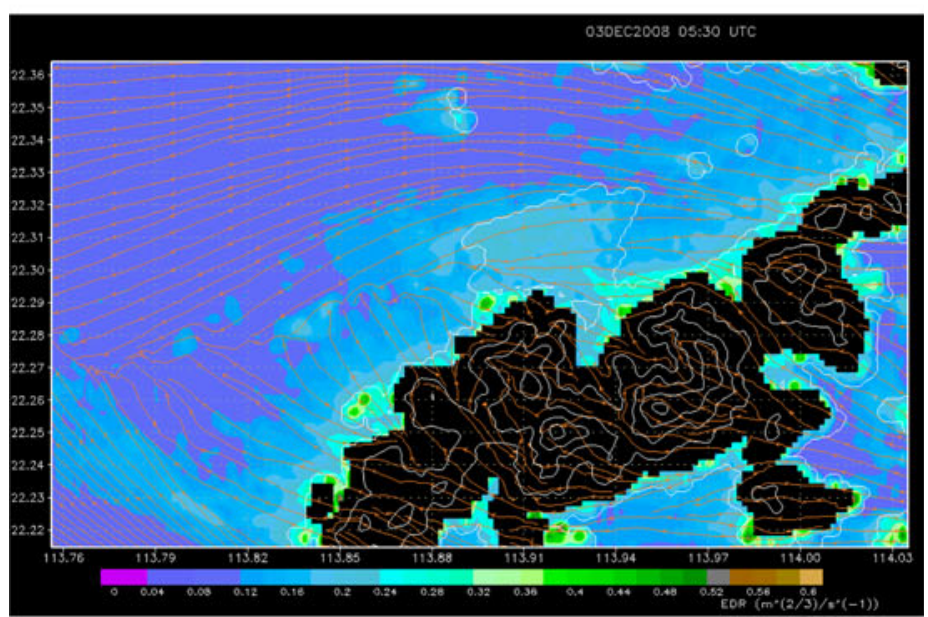

(c) 
The EDR ${ }^{1 / 3}$ profiles at SLW and SHW are qualitatively compared with model simulation results in Fig. $6 \mathrm{a}$ and b, respectively. The e-1 scheme and Deardorff scheme give $\mathrm{EDR}^{1 / 3}$ values that are generally consistent with the actual observations up to about $1,000 \mathrm{~m}$. At higher altitudes, the forecast $\mathrm{EDR}^{1 / 3}$ values fall with height too rapidly. Similar to the previous case, the Mellor-Yamada scheme in general gives too small $\mathrm{EDR}^{1 / 3}$ values in various altitudes. It is interesting to note that, for e-1 scheme, if $c_{\mu}$ is taken to have a too low value (e.g. 0.1), the resulting $\mathrm{EDR}^{1 / 3}$ curve is quite close to the wind profiler data at Sha Lo Wan. On the other hand, the comparison with the actual data is not so good for low value of $c_{\mu}$, as also reported in the previous case (Sect. 4).

\section{Spring-time easterly case}

Easterly flow in a stable boundary layer also occurs in the spring time. Due to the mountainous terrain of Lantau Island, mountain wake and other terrain-induced airflow

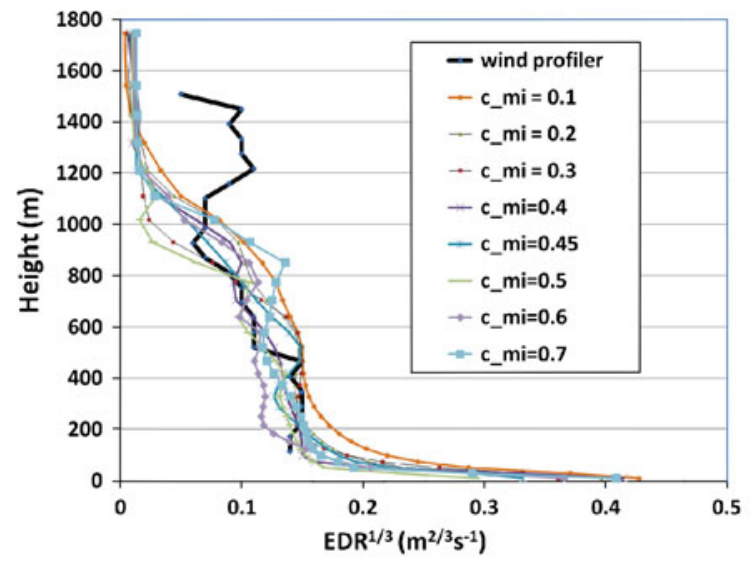

best performing: c_mi $=0.4$

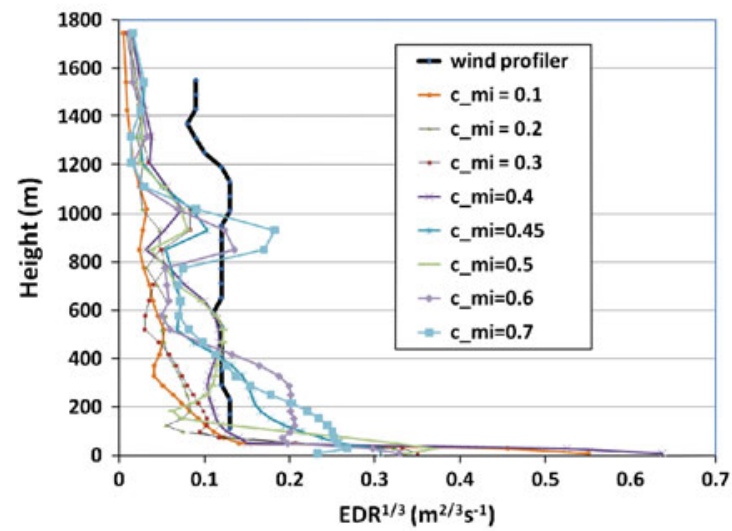

best performing: $\mathrm{c}$ - $\mathrm{mi}=0.4$ disturbances would appear in the vicinity of HKIA. The present case is similar to that discussed in Sect. 5, but with slightly higher wind speed for the easterly wind and thus more turbulent airflow just downstream of Lantau Island. This case is used to illustrate the performance of e-l scheme in slightly more turbulent airflow and the optimum value of $c_{\mu}$

The LIDAR's radial velocity imagery is shown in Fig. 7a. It could be seen that there is a mountain wake (reverse flow with lower wind speed) to the southwest of HKIA. RAMS simulation is performed starting at 00 UTC, 8 February 2010, and the simulation results at 01:30 UTC is presented here. Using e-1 scheme with $c_{\mu}=0.45$ (within the optimal range of $0.4-0.5$ for $c_{\mu}$, as in Xu and Taylor 1997), the moderate to fresh easterly airstream over HKIA and the mountain wake to the southwest of the airport could be simulated successfully (Fig. 7b). In particular, the mountain wake appears as a vortex with a diameter of a couple of kilometres just downstream of the mountains of Lantau Island. The corresponding $\mathrm{EDR}^{1 / 3}$ plot is given in Fig. 7c. Light to moderate turbulence $\left(\mathrm{EDR}^{1 / 3}\right.$ in the order

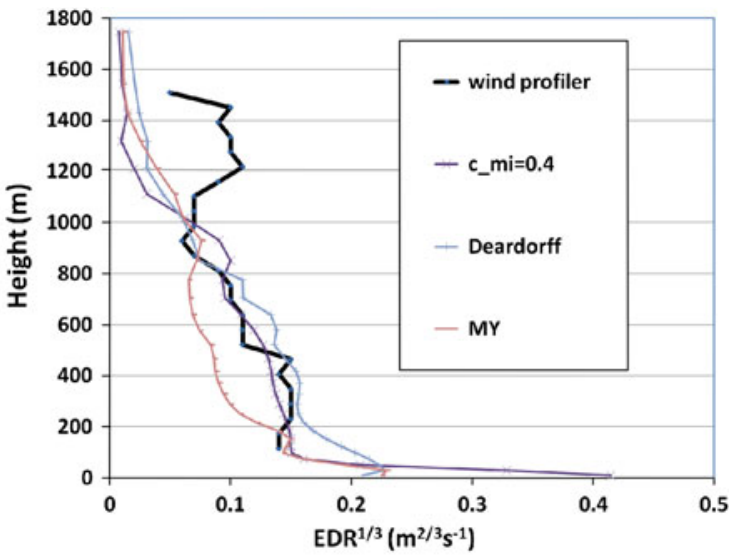

(a)

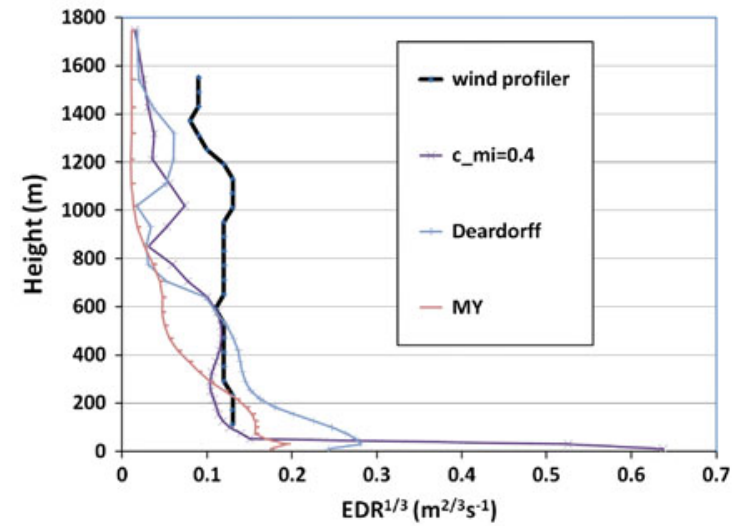

(b)

Fig. 6 Same as Fig. 4 but for the winter monsoon case at 05:30 UTC, 3 December 2008 
Fig. 7 Same as Fig. 3 but for the spring-time easterly wind case at 01:30 UTC, 8 February 2010

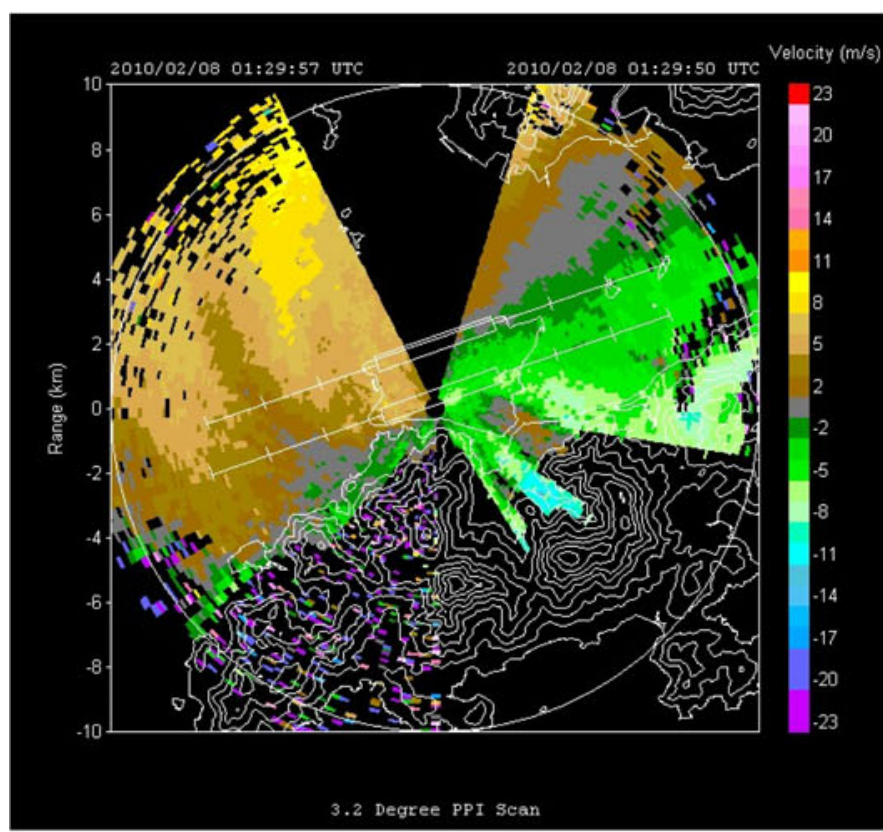

(a)

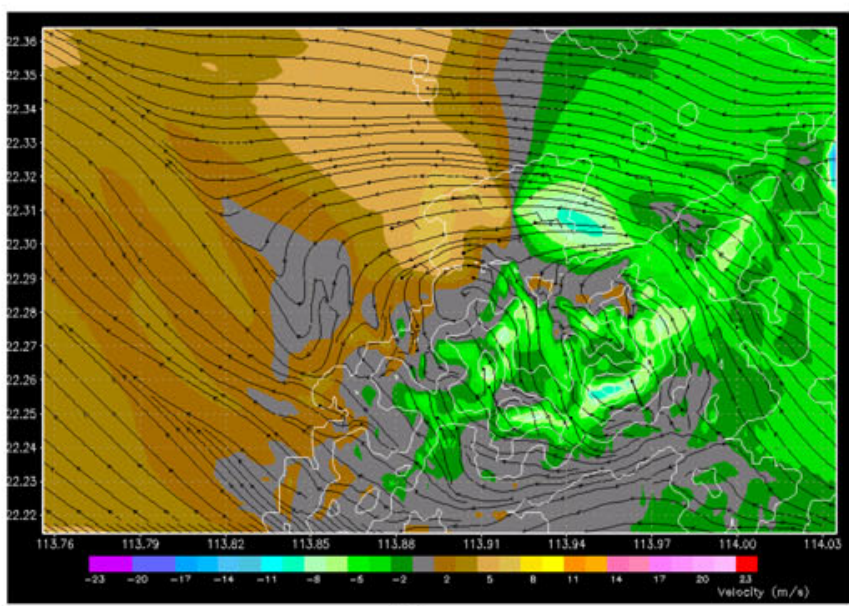

(b)

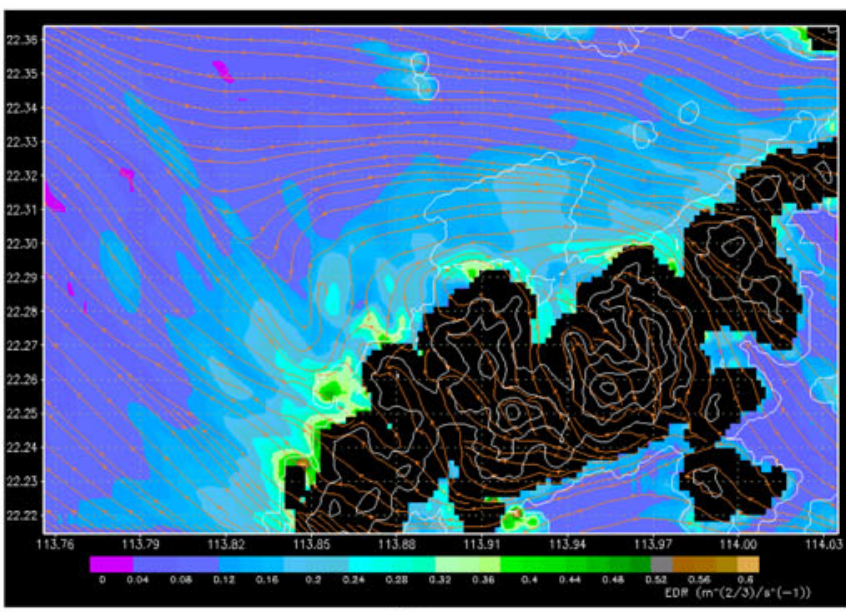

(c) 
of $0.2-0.3 \mathrm{~m}^{2 / 3} \mathrm{~s}^{-1}$ ) is simulated off the northern coast of Lantau.

The simulated turbulence intensity is qualitatively compared with wind profiler measurements in Fig. 8 at Sha Lo Wan and Siu Ho Wan. It could be seen that, at Sha Lo Wan, the e-l scheme basically successfully reproduces the $\mathrm{EDR}^{1 / 3}$ profile. The optimum value of $c_{\mu}$ is about 0.45 , i.e. the use of this value for $c_{\mu}$ gets the $\mathrm{EDR}^{1 / 3}$ profile that is closest to the actual measurement. However, at Siu Ho Wan, the model underestimates the $\mathrm{EDR}^{1 / 3}$ value, even though the order of magnitude of the simulated $\mathrm{EDR}^{1 / 3}$ is similar to the actual measurement at least in the first few hundred metres above ground where the effect of low-level turbulence on aircraft operation is more significant. The lower turbulence intensity in the simulation may be related to the occurrence of a more extensive mountain wake near Siu Ho Wan in the simulated airflow (Fig. 7b), whereas in reality the wind speed is higher in that region (Fig. 7a). Given the complexity of the Lantau terrain and the sensitivity of the airflow downstream of Lantau to the upstream wind and temperature profiles, the performance of the

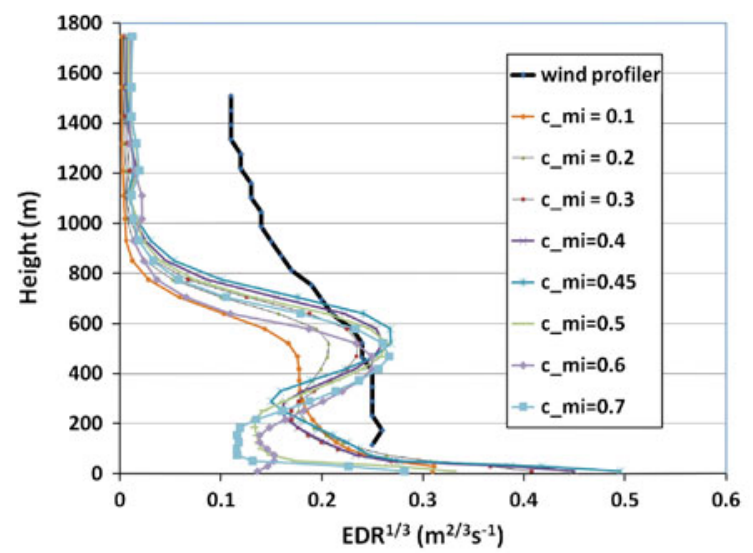

best performing: c_mi $=0.45$

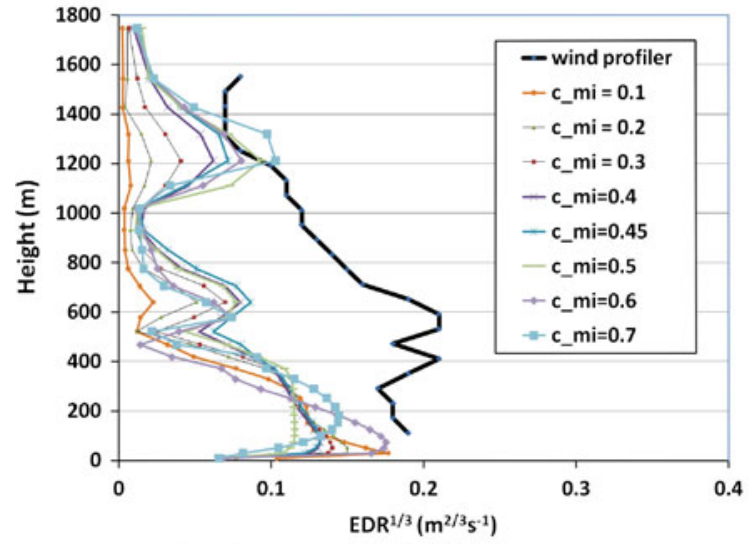

best performing: c $\mathrm{mi}=0.45$
RAMS simulation results is considered to be generally satisfactory. For the e-l scheme, in general with higher value of $c_{\mu}$ (optimal value of $0.4-0.5$ vs. low value of 0.1 ), the resulting $\mathrm{EDR}^{1 / 3}$ curve is closer to the wind profiler data.

\section{Tropical cyclone case}

In order to test the performance of e-l scheme in a more challenging meteorological condition, the strong easterly winds associated with Typhoon Neoguri on 19 April 2008 are considered. In the afternoon on that day, Neoguri was located at around $250 \mathrm{~km}$ west-southwest of Hong Kong and was about to make landfall over southern coast of China. The Doppler velocity measured by TDWR at 06:32 UTC is shown in Fig. 9a. This figure shows the spatial distribution of the line-of-sight velocity with respect to the TDWR. Similar to the discussion in Sect. 4, the winds around HKIA are not uniform and streaks of higher and lower wind speeds could be seen in the region.

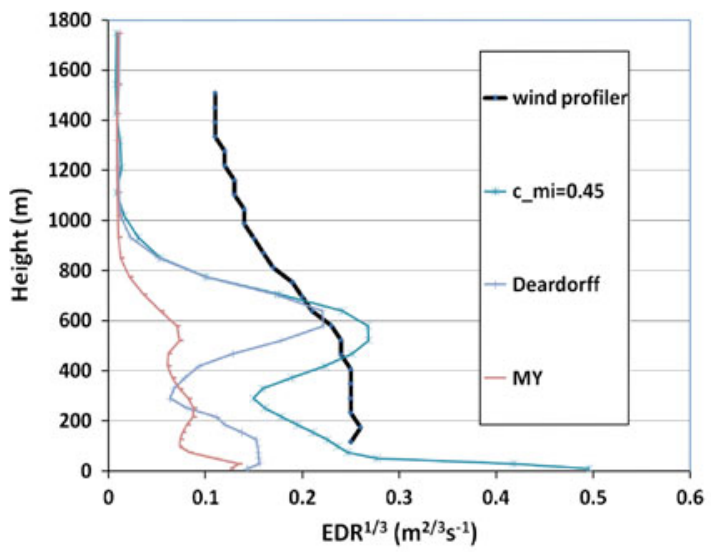

(a)

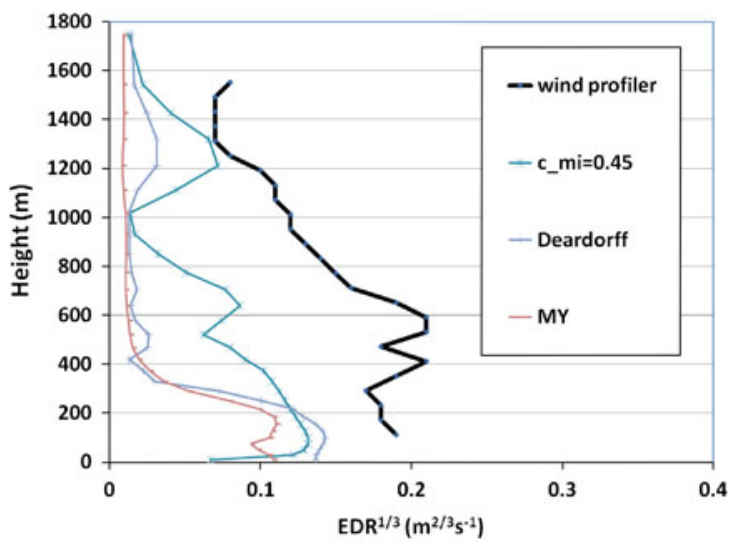

(b)

Fig. 8 Same as Fig. 4 but for the spring-time easterly wind case at 01:30 UTC, 8 February 2010 
Fig. 9 The tropical cyclone case at 06:32 UTC, 19 April 2008. a is the Doppler velocity imagery from TDWR (i.e. lineof-sight velocity directly measured by the TDWR), $\mathbf{b}$ is the model-simulated radial velocity of TDWR at a height of $210 \mathrm{~m}$, and $\mathbf{c}$ is the corresponding $\mathrm{EDR}^{1 / 3}$ field

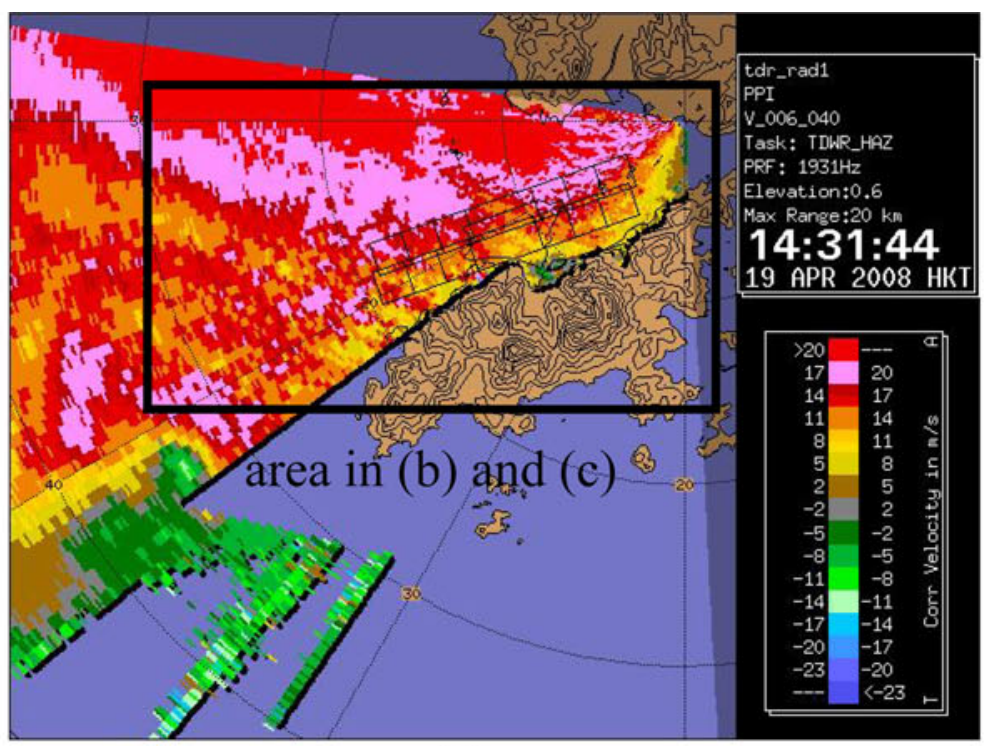

(a)

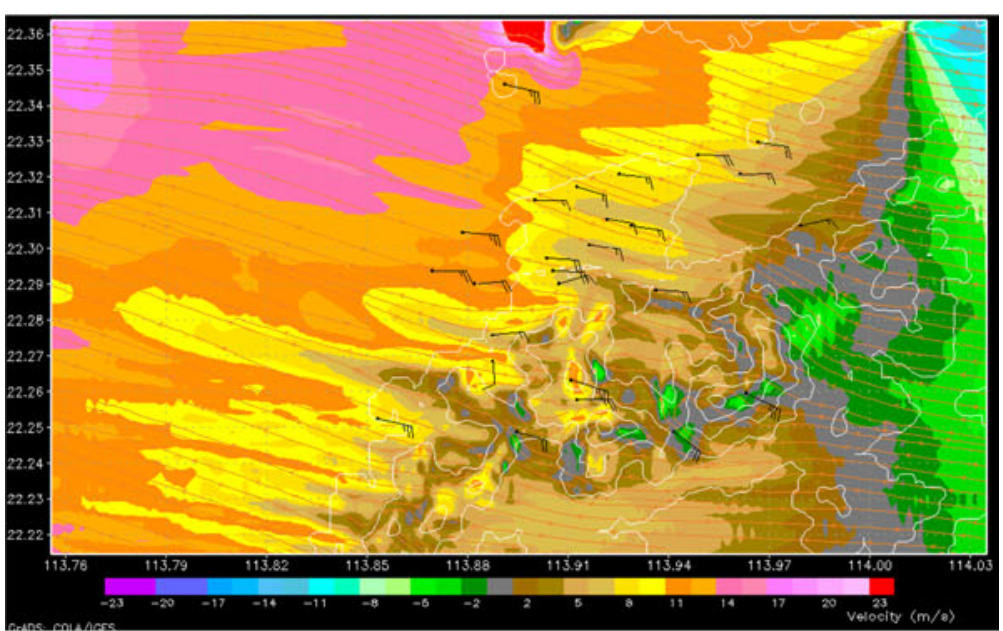

(b)

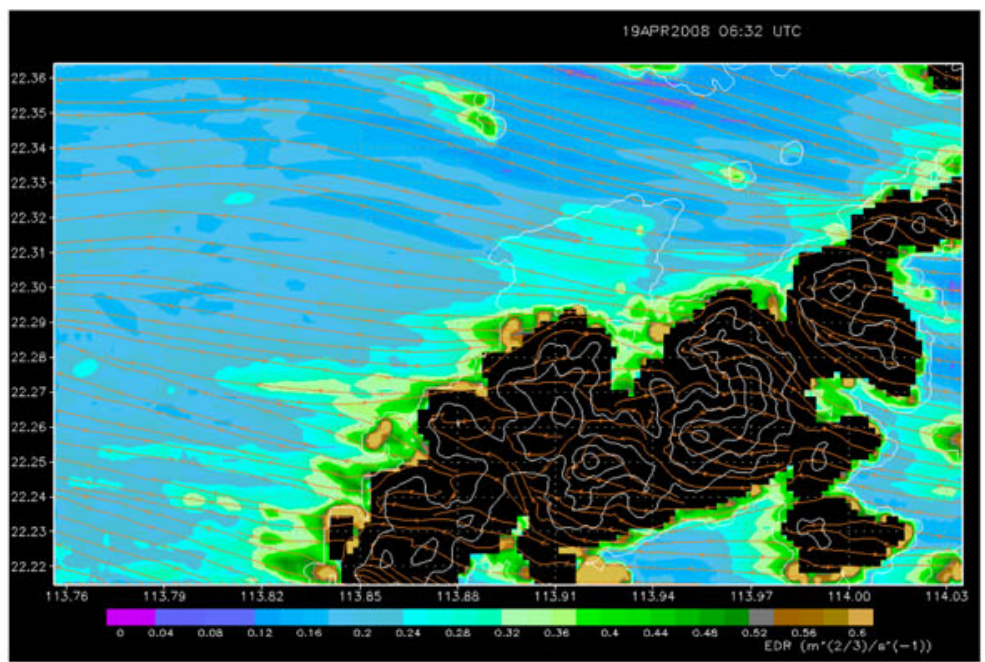

(c) 
Once again, such streaks appear to arise from airflow disruption by Lantau terrain. They have been documented in other tropical cyclone cases, e.g. in Chan and Shao (2007).

The model simulation starts at 06:00 UTC, 19 April 2008. The use of Mellor-Yamada scheme or Deardorff scheme manages to give simulation results at least for $12 \mathrm{~h}$. However, e-1 scheme is rather unstable no matter what the value of $c_{\mu}$ was. Simulation could only be done up to about half an hour and afterwards the Courant-Friedrich-Levy (CFL) limit is exceeded. This situation appears for different choices of the time steps (e.g. even when the time step is reduced to a few seconds for the innermost domain of the simulation). However, from the model simulation results, it appears that the terrain disruption of the airflow has been developed to a considerable extent despite the rather short period of the model simulation. For instance, the modelsimulated wind field using the e-1 scheme with $c_{\mu}=0.4$ is shown in Fig. 9b. In this case, the simulated radial velocity of the TDWR is depicted. It could be seen that there are streaks of higher and lower wind speeds in the easterly flow downstream of Lantau Island, and the results are generally consistent with the actual TDWR observations. Please note that Fig. 9a refers to the line-of-sight velocity with respect to the TDWR only, but not the full 2D velocity vector, which is not measured directly with the radar.

The model-simulated $\mathrm{EDR}^{1 / 3}$ field at that time is given in Fig. 9c. Compared with the winter-time case in Sect. 5, the turbulence intensity is much higher downstream of the mountains in the present case. This is possibly related to the mechanical generation of stronger turbulence in higher wind speed.

The $\mathrm{EDR}^{1 / 3}$ profiles at SLW and SHW are qualitatively compared with model simulation results in Fig. 10a and b, respectively. Compared with the previous two cases, the model-simulated profiles do not perform so well in typhoon situation. For e-l scheme, the turbulence near ground is unreasonably high. Though wind profiler data are not available in such heights, $\mathrm{EDR}^{1 / 3}$ values determined from conical scans of the LIDAR do not support the occurrence of turbulence intensity in the order of $1 \mathrm{~m}^{2 / 3} \mathrm{~s}^{-1}$ (not

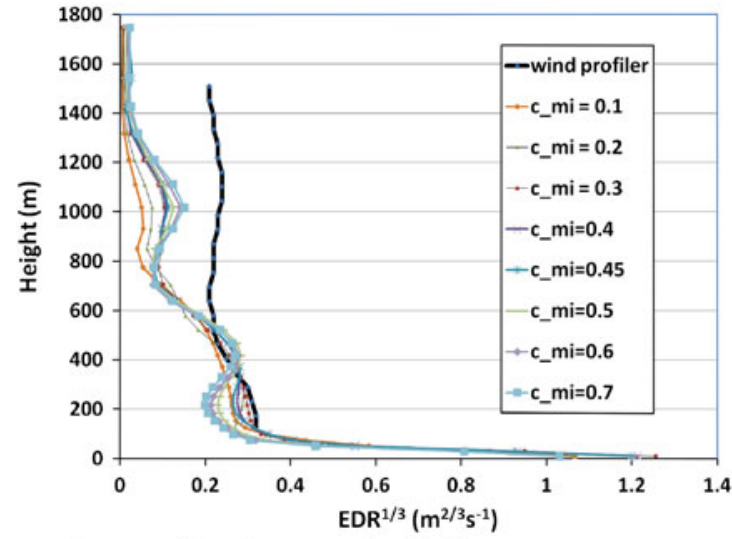

best performing: c_mi $=0.45$

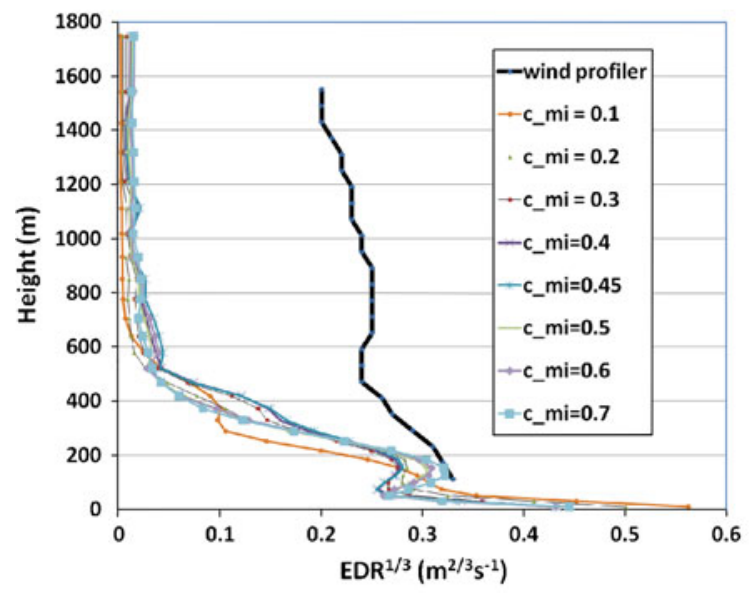

best performing: c_mi $=0.45$

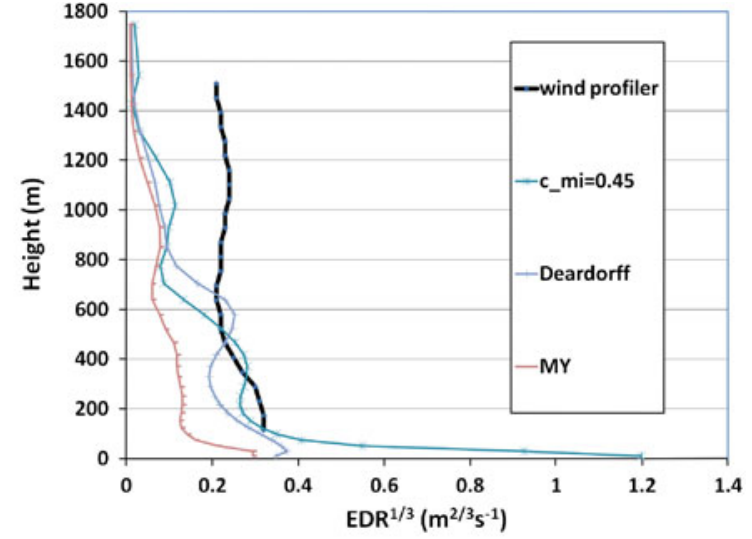

(a)

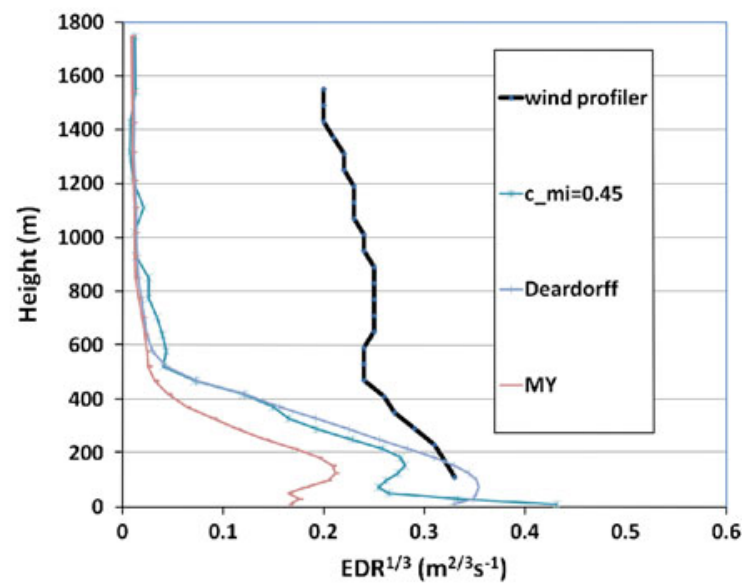

(b)

Fig. 10 Same as Fig. 4 but for the tropical cyclone case at 06:32 UTC, 19 April 2008 
shown). Then $\mathrm{EDR}^{1 / 3}$ values have magnitudes comparable with the actual observations up to several hundred metres (600 $\mathrm{m}$ in SLW and $200 \mathrm{~m}$ in SHW). Further aloft, EDR ${ }^{1 / 3}$ drops with height too rapidly, which has also been observed in previous typhoon simulation results (Chan 2009). Deardorff scheme does not give the unreasonably higher $\mathrm{EDR}^{1 / 3}$ near ground. For Mellor-Yamada scheme, similar to the southwest monsoon case, the $\mathrm{EDR}^{1 / 3}$ values at various altitudes are generally too small. For e-1 scheme, the differences in the resulting $\mathrm{EDR}^{1 / 3}$ curves are not so significant with different values of $c_{\mu}$.

The study of the performance of e-1 scheme in tropical cyclone situation may be limited because of the short simulation time (about half an hour) that could be achieved. The wind field may not have been fully adapted to the terrain for the innermost domain (in which the Lantau Island is present). The results in the present section should be interpreted with that perspective. Model simulation has been performed for this tropical cyclone case at an earlier time, e.g. $12 \mathrm{~h}$ ago (starting from $18 \mathrm{UTC}, 18$ April 2008). The resulting wind and turbulence fields are similar to those presented in this paper. Simulations starting at even earlier time have not been attempted because the forecast locations of the tropical cyclone with respect to Hong Kong in ORSM become rather different from that predicted in the run starting at 06 UTC, 19 April 2008.

\section{Optimal value of $c_{\mu}$}

The root-mean-square (r.m.s.) differences between the model-simulated results and the actual measurements of $\mathrm{EDR}^{1 / 3}$ between 120 and $1,500 \mathrm{~m}$ (the first and the last range gates of the wind profilers in low mode) have been calculated as a function of $c_{\mu}$. The results for SLW and SHW are given in Fig. 11a and b, respectively. It could be seen that:

1. The "optimal" $c_{\mu}$ value giving the smallest r.m.s differences is about 0.4-0.45. This is consistent with the results in the literature (between 0.40 and 0.55 ).

2. The r.m.s. differences are much greater for the tropical cyclone case than the moderate wind cases.

The r.m.s. differences for e-l scheme are also compared with those for Deardorff scheme and Mellor-Yamada scheme, as shown in Table 1. It could be seen that, using an optimal value of $c_{\mu}$, the use of e-l scheme with a variable asymptotic mixing length gives results that are comparable with the best turbulence parameterization scheme, namely, Deardorff scheme, as found out in the previous case (Chan 2007). The major challenge for e-l scheme would then be the instability in strong wind situation (e.g. tropical cyclone case in Sect. 7). On the other hand,

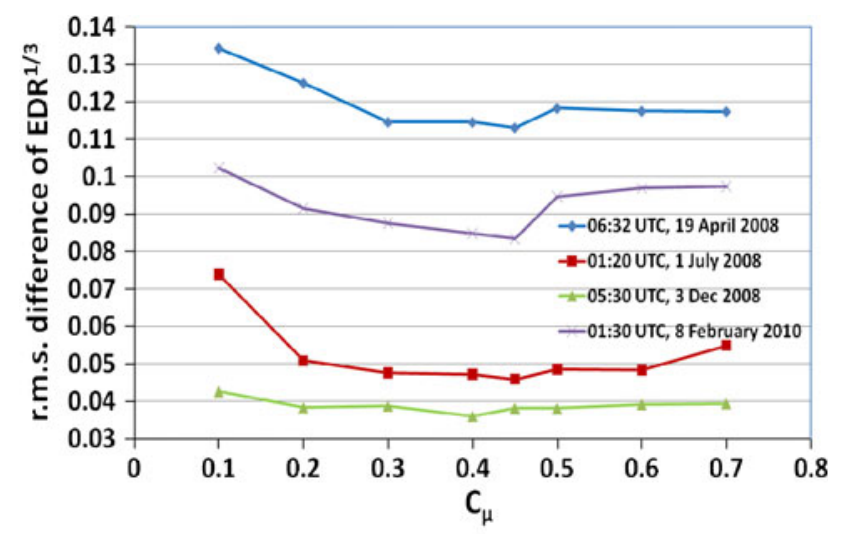

(a)

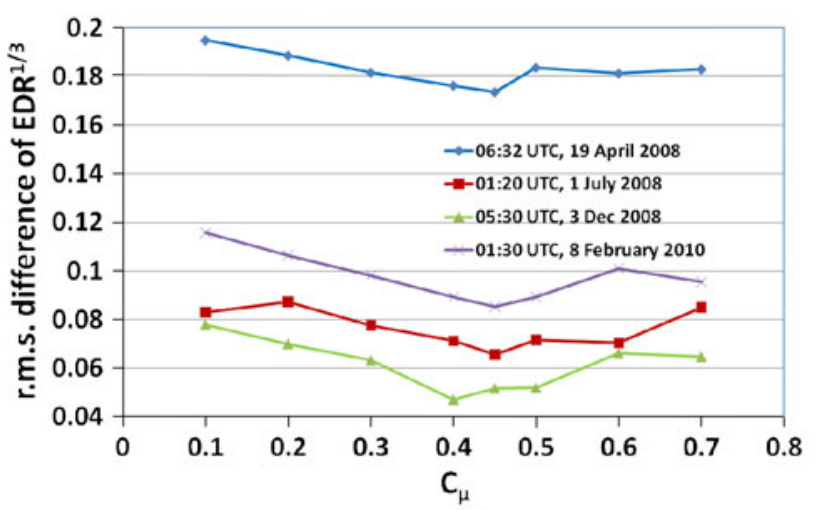

(b)

Fig. 11 The r.m.s. difference between model-simulated and actual measurement of EDR ${ }^{1 / 3}$ as a function of $c_{\mu}$ value in e-l scheme for the wind profiler at a Sha Lo Wan and b Siu Ho Wan

Mellor-Yamada scheme generally gives too small EDR ${ }^{1 / 3}$ values and thus the r.m.s. differences are the largest among the three schemes.

For e-1 scheme and Deardorff scheme, the r.m.s differences with actual observations are generally in the order of $0.03-0.07 \mathrm{~m}^{2 / 3} \mathrm{~s}^{-1}$ in moderate wind situation. This is still lesser than $0.1 \mathrm{~m}^{2 / 3} \mathrm{~s}^{-1}$. As such, the forecast $\mathrm{EDR}^{1 / 3}$ fields by these turbulence parameterization schemes could be useful in the monitoring of low-level turbulence in an area of complex terrain, which is a safety hazard to the aircraft. On the other hand, the performance in tropical cyclone cases is more questionable. The simulation results for Deardorff scheme could still be useful for the monitoring of low-level turbulence in the first few hundred metres or so, as discussed in Chan (2009). However, the results of e-1 scheme should be treated with caution in view of the unreasonably large values of $\mathrm{EDR}^{1 / 3}$ near ground.

\section{Effect of vertical gridding}

In Chan (2009), a fixed vertical gridding is used for all model simulations, namely, with a stretching ratio of 1.15 
Table 1 The r.m.s. differences between the model-simulated EDR ${ }^{1 / 3}$ profiles and the actual measurements from the wind profiler at Sha Lo Wan and Siu Ho Wan for the various turbulence parameterization schemes

\begin{tabular}{llll}
\hline & $\begin{array}{c}\text { Mellor- } \\
\text { Yamada }\end{array}$ & Deardorff & $\begin{array}{l}\text { e-1 scheme } \\
\text { (best performing) }\end{array}$ \\
\hline $\begin{array}{l}\text { Sha Lo Wan } \\
\text { 19 April 2008 }\end{array}$ & 0.172 & 0.123 & 0.113 \\
1 July 2008 & 0.102 & 0.041 & 0.046 \\
3 December 2008 & 0.043 & 0.034 & 0.036 \\
8 February 2010 & 0.154 & 0.121 & 0.083 \\
Siu Ho Wan & & & \\
19 April 2008 & 0.199 & 0.173 & 0.174 \\
1 July 2008 & 0.103 & 0.073 & 0.066 \\
3 December 2008 & 0.071 & 0.060 & 0.047 \\
8 February 2010 & 0.127 & 0.120 & 0.085 \\
\hline
\end{tabular}

according to the vertical gridding method of RAMS. As an illustration of the potential effect of vertical gridding on the simulation results of turbulence intensity profile, a case study is considered in this paper, namely, southerly winds in the morning of 1 July 2008. Moreover, for simplicity, only the Deardorff scheme is used in this case study. Three vertical griddings have been used, namely, with a stretching ratio of $1.15,1.35$ and 1.55 .

The $\mathrm{EDR}^{1 / 3}$ distribution obtained from LIDAR data at 01:18 UTC, 1 July 2008 is shown in Fig. 12a. Due to the mountains on Lantau Island, the area of moderate turbulence extends up to about $6 \mathrm{~km}$ downstream of this island. However, at the same time there are some "narrow streaks" of lower turbulence, reaching the level of light turbulence only (coloured blue in Fig. 12a). They appear to originate from the gaps of Lantau Island. As such, the mechanical turbulence associated with the cross-mountain flow brings about moderate turbulence to the areas in the vicinity of the airport, but at the same time the airflow through the gaps has light turbulence only.

The above features of turbulence distribution could largely be reproduced from RAMS simulations. The simulated $\mathrm{EDR}^{1 / 3}$ patterns with different vertical griddings are very similar, as shown in Fig. 12b-d. The height of about $300 \mathrm{~m}$ is considered in the model simulations, which is about the height of the location of light turbulence gap flow to the east of the airport.

Though the general turbulence patterns are largely the same, the magnitudes of the simulated $\mathrm{EDR}^{1 / 3}$ values could be quite different with the use of the different vertical griddings. The forecast $\mathrm{EDR}^{1 / 3}$ profiles from the three grids are compared with the actual measurements from Sha Lo Wan and Siu Ho Wan wind profilers in Fig. 13. It could be seen that the vertical gridding used in the previous results and in Chan (2009), namely, a stretching ratio of 1.15 , gives the best comparison results with the actual data. With coarser vertical grids, the $\mathrm{EDR}^{1 / 3}$ values tend to be overforecast.

\section{Light turbulence case}

The cases considered so far (in the present paper and in Chan 2009) are moderate to severe turbulence situations. In order to apply the model forecasting results to actual turbulence alerting, the possibility of producing false alarms from the model simulations has to be considered, for instance, for light turbulence situation, the model should not over-forecast the values of $\mathrm{EDR}^{1 / 3}$. In order to study this aspect, a light turbulence case is considered, namely, light to moderate northeasterly winds on 6 November 2009, when the southern China was under the influence of moderate northeast monsoon.

The model run starts from 00 UTC, 6 November 2009. For simplicity, only the Deardorff scheme is considered in the present case. The results at 08:20 UTC are considered. The LIDAR EDR ${ }^{1 / 3}$ distribution is shown in Fig. 14a. It could be seen that turbulence is generally light in the vicinity of the airport. Higher turbulence occurs in the areas: (1) downstream of the mountains to the north of the airport, and (2) to the east of LIDAR over the airport.

The model-simulated $\mathrm{EDR}^{1 / 3}$ pattern is given in Fig. 14b. The above-described features of turbulence distribution are reproduced reasonably well. In general, the model forecasts light turbulence only around the airport, and thus there does not appear to be an over-forecast problem. To study the numeric values of $\mathrm{EDR}^{1 / 3}$ more critically, the model-simulated $\mathrm{EDR}^{1 / 3}$ profiles are compared with the actual measurements by the Sha Lo Wan and Siu Ho Wan wind profilers in Fig. 15. It could be seen that the model results and the actual data have comparable magnitude as well as similar vertical distribution of turbulence intensity. Based on the results of the present case, it appears that RAMS performs equally well in handling light turbulence situation.

\section{Simulation of TKE}

The studies so far concentrate on $\mathrm{EDR}^{1 / 3}$, which is the intentionally adopted metric for turbulence intensity in aviation application. Other metrics have been considered for aviation purpose, such as TKE. The performance of RAMS in the simulation of TKE has also been examined in a couple of examples. Deardorff scheme is employed in all the simulations.

The first example is the spring-time easterly wind case on 8 February 2010. The model-simulated TKE profiles at 


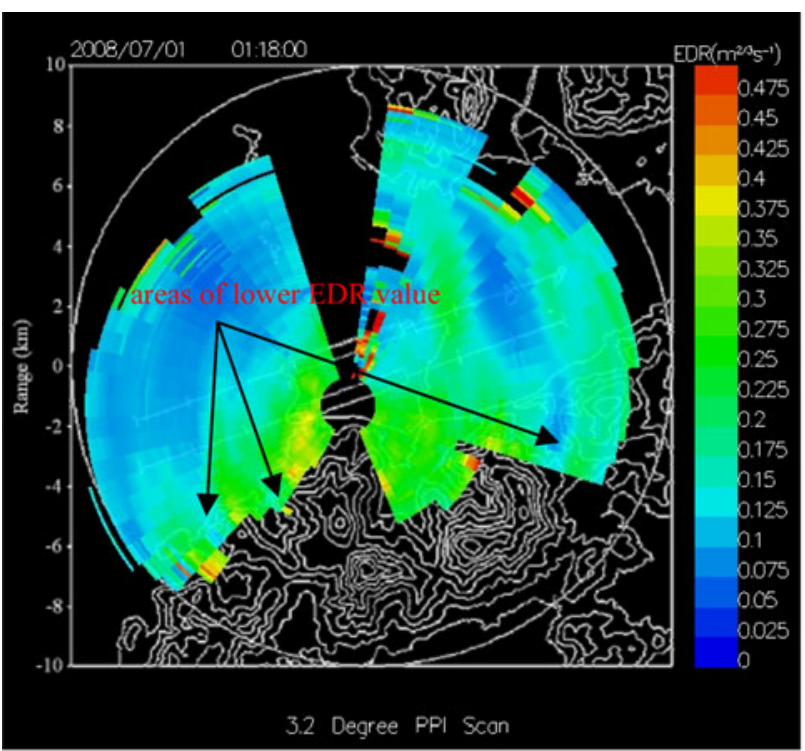

(a) LIDAR-based EDR distribution

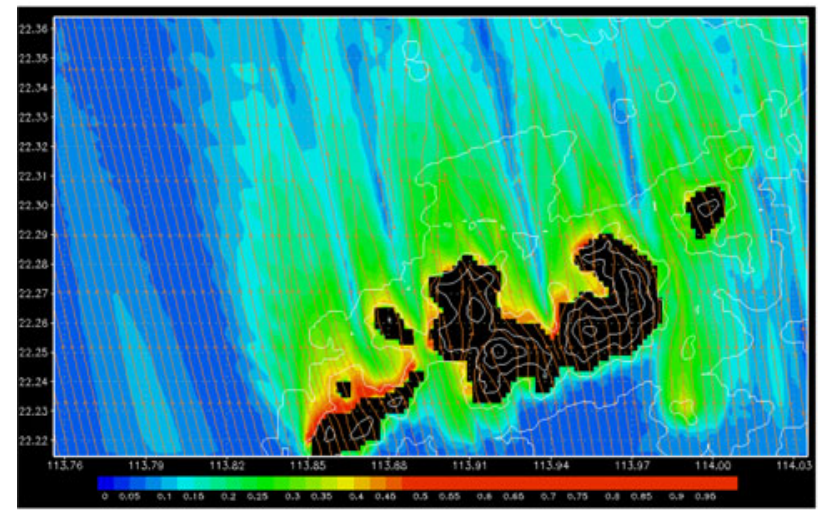

(c) stretching ratio 1.35, at a height of $294 \mathrm{~m}$

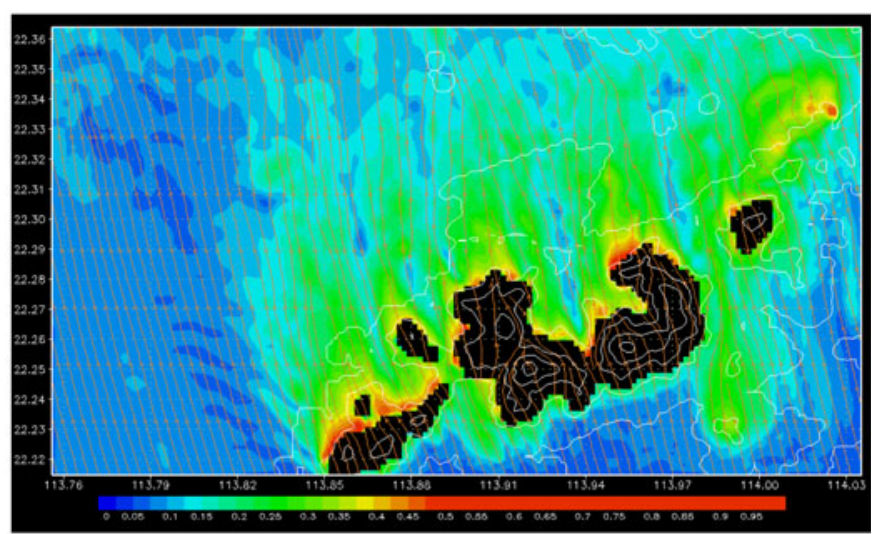

(b) stretching ratio 1.15 , at a height of $289 \mathrm{~m}$

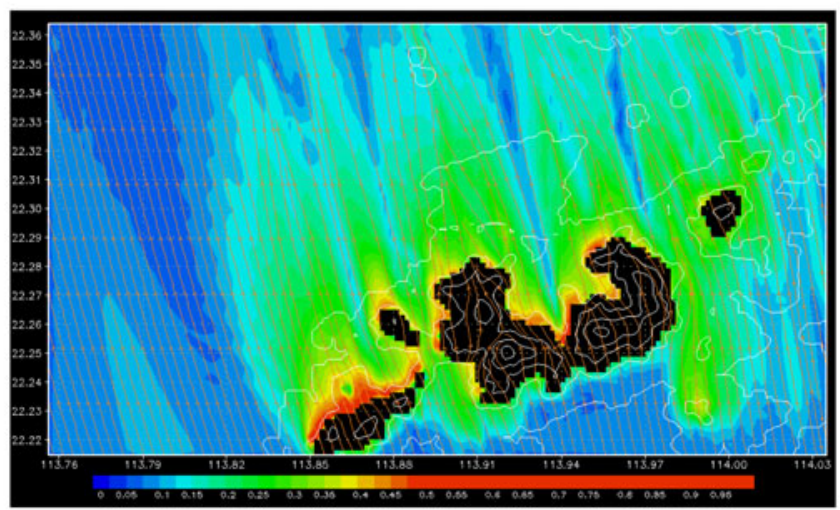

(d) stretching ratio 1.55 , at a height of $303 \mathrm{~m}$

Fig. 12 a Is the LIDAR-estimated $\mathrm{EDR}^{1 / 3}$ distribution in the vicinity of the airport at 01:18 UTC, 1 July 2008. The model-simulated results are given in $\mathbf{b}, \mathbf{c}$ and $\mathbf{d}$, corresponding to the use of vertical grids with the stretching ratio $1.15,1.35$ and 1.55 , respectively (colour figure online)

shoreline anemometer site (location in Fig. 1) with different vertical griddings (namely, stretching ratios of 1.15, 1.35 and 1.55) are shown in Fig. 16a. It appears that, with a coarser grid the TKE tends to be higher within the first couple of hundred metres or so above ground.

In order to assess the quality of the model-simulated TKE, the actual measurements by the minisodar at shoreline anemometer site has been considered. Data are available up to about $200 \mathrm{~m}$ above sea level, and they are plotted in Fig. 16a. Simulation is carried out starting from 00 UTC, 8 February 2010 and the simulation results after $3 \mathrm{~h}$ are used. The simulated TKE profile with a vertical gridding of the stretching ratio of 1.15 seems to be generally consistent with the actual measurements. This comparison result supports the use of the stretching ratio of
1.15 for the vertical gridding in the simulation study for easterly flow.

Another case is considered here is the stronger turbulence in the southerly wind case of 5 March 2010. Simulation is carried out starting from 00 UTC, 5 March 2010 and the simulation results after $7 \mathrm{~h}$ are considered. The sodar-measured profile and the model-simulated profile of TKE are compared in Fig. 16b. Again, the actual profile appears to be captured well by the model simulation (Deardorff scheme, stretching ratio of 1.15 for the vertical gridding), though the simulated results have higher values of TKE. The simulation results based on the stretching ratio of 1.15 for vertical gridding have the best comparison with the actual observations, which supports the selection of this stretching ratio value. 


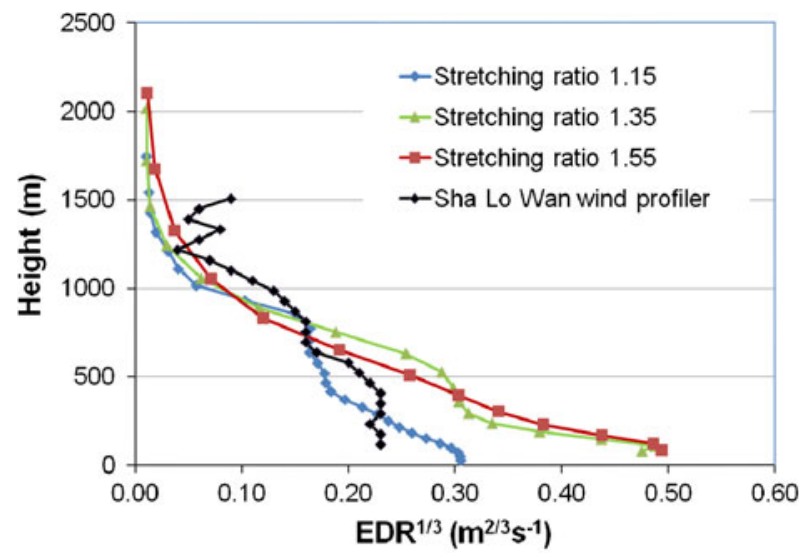

(a)

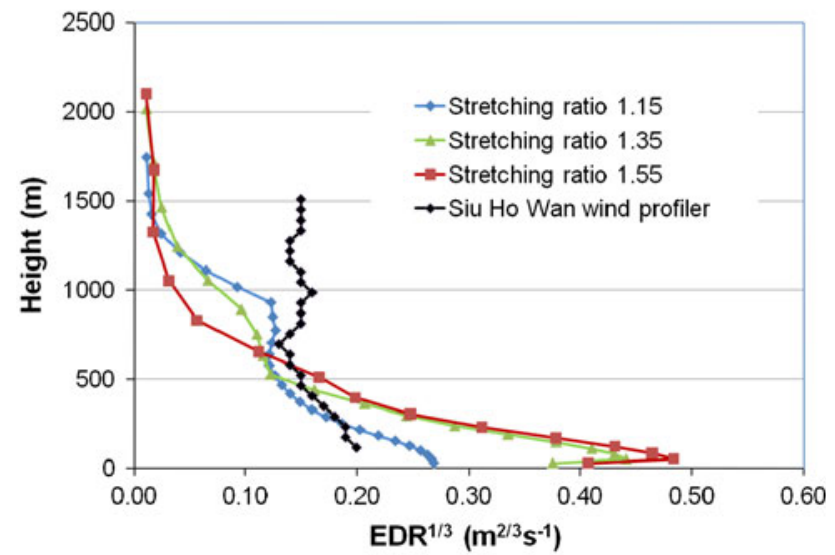

(b)

Fig. 13 Comparison between $\mathrm{EDR}^{1 / 3}$ obtained from the wind profiler and the simulation results for a Sha Lo Wan, and b Siu Ho Wan. The model simulations include the use of vertical co-ordinates with stretching ratios $1.15,1.35$ and 1.55

The minisodar with a measurement range of $200 \mathrm{~m}$ has been working at the airport since January 2010. More data would be collected for assessing the performance of RAMS simulations of TKE, e.g. in summer monsoon and tropical cyclone situations.

\section{Conclusions}

The e-l turbulence parameterization scheme and the other more conventional schemes, such as Mellor-Yamada (1982) and Deardorff (1980) in RAMS, have been studied in this paper by simulating turbulence intensity for terraindisrupted airflow in various weather conditions. The conclusions of this study include:

(a) By choosing an optimal value of $c_{\mu}$ and the use of variable asymptotic mixing length, the performance of e-l scheme could be comparable with the bestperforming turbulence parameterization scheme as

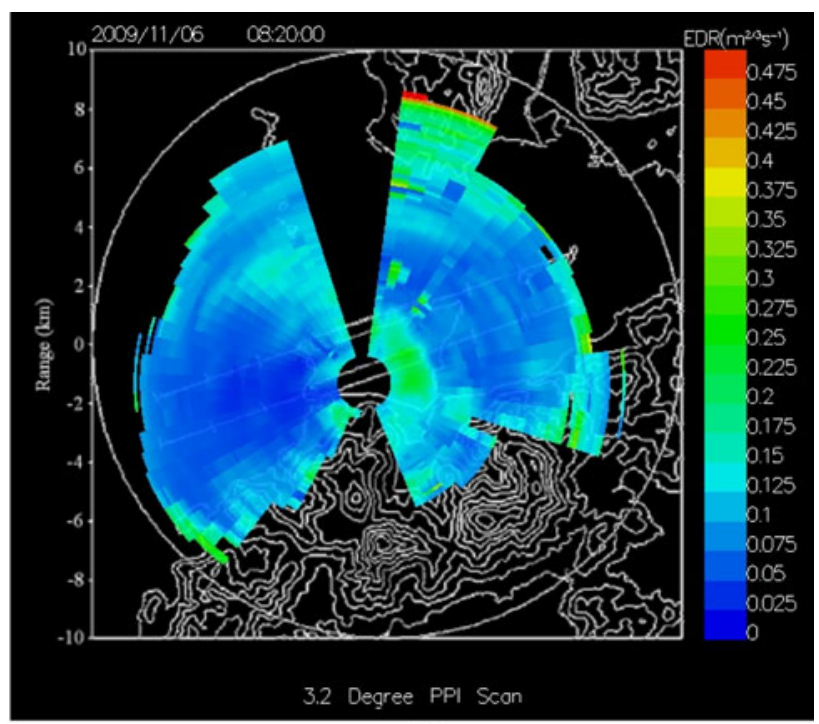

(a)

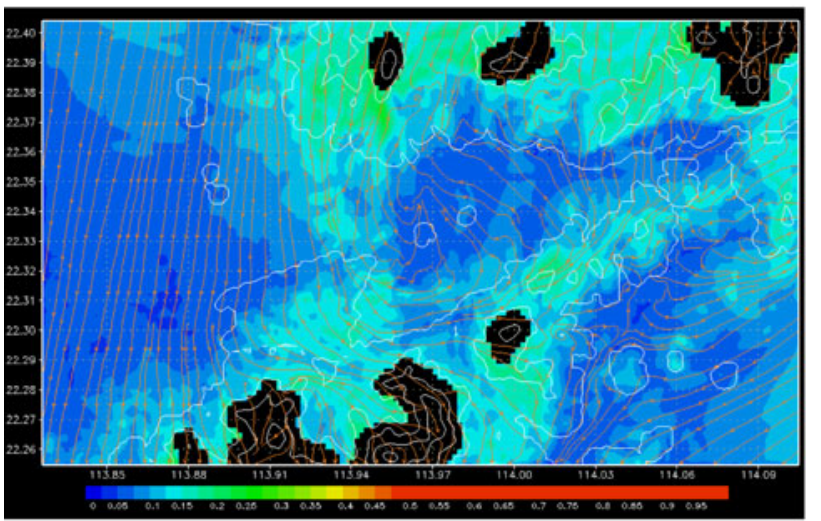

(b)

Fig. 14 LIDAR-derived EDR ${ }^{1 / 3}$ at 08:20 UTC, 6 November 2009 (a). The model-simulated results at a height of $289 \mathrm{~m}$ is given in $\mathbf{b}$

found in the previous study, namely, Deardorff (1980) scheme, for moderate winds.

(b) Considering r.m.s. difference between the modelsimulated results and the radar wind profiler measurements, the optimal value of $c_{\mu}$ in the e-1 scheme is found to be $0.4-0.45$, which is consistent with the results in the literature.

(c) The e-l scheme requires further improvements in strong wind situations, e.g. in association with tropical cyclones. Numerically, the scheme is very unstable in strong winds. Meteorologically, it gives unreasonably high $\mathrm{EDR}^{1 / 3}$ values near ground, which is not supported in the available observations. Please note that, for the simulations presented in this paper, the model-simulated wind and turbulence fields have been output every minute and such fields have been found to develop fully in general in response to the complex terrain at the Hong Kong International 


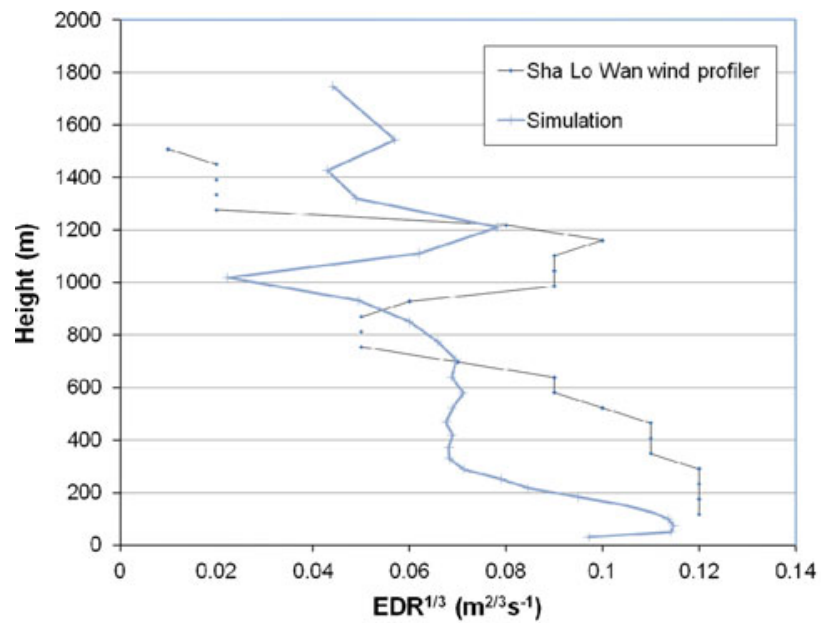

(a)

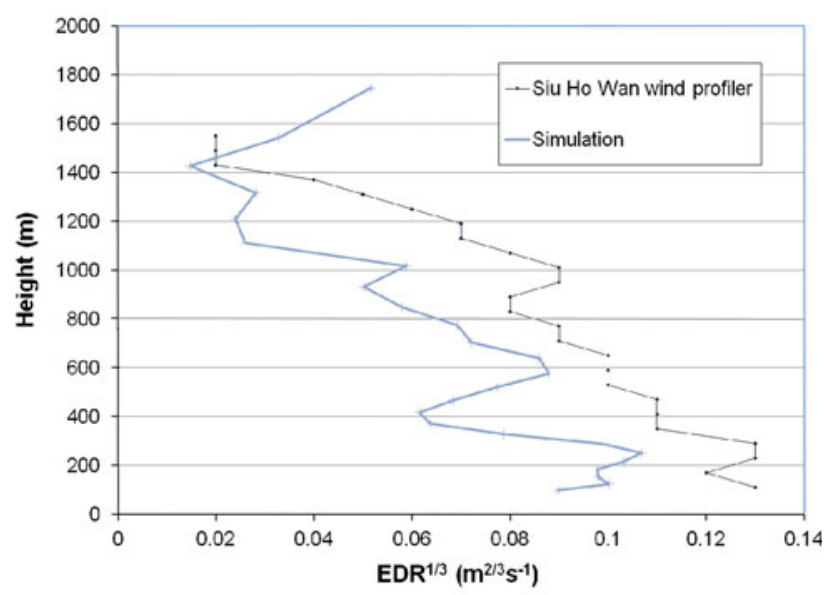

(b)

Fig. 15 Model-simulated EDR ${ }^{1 / 3}$ profile compared with the wind profiler data at a Sha Lo Wan, and b Siu Ho Wan

Airport (e.g. the horizontal extent of the wake downstream of the mountains on Lantau Island remains basically the same) though the simulation times are relatively short, particularly for the e-1 scheme (apart from the tropical cyclone situation on 19 April 2008).

(d) The Deardorff (1980) scheme is still found to be the most robust among the turbulence parameterization schemes available in RAMS. The only shortcoming is that, for strong winds in tropical cyclone situations, the $\mathrm{EDR}^{1 / 3}$ values fall with height too rapidly in comparison with actual observations. Nonetheless, the forecast $\mathrm{EDR}^{1 / 3}$ field is still found to be useful in the monitoring of low-level turbulence, which is a safety hazard to the aircraft. For this purpose, the e-1 scheme (with an optimal value of $c_{\mu}$ ) could also be used in moderate wind situations.

The Mellor-Yamada (1982) scheme is an ensemble 1D scheme that uses only vertical mixing. There is an issue of

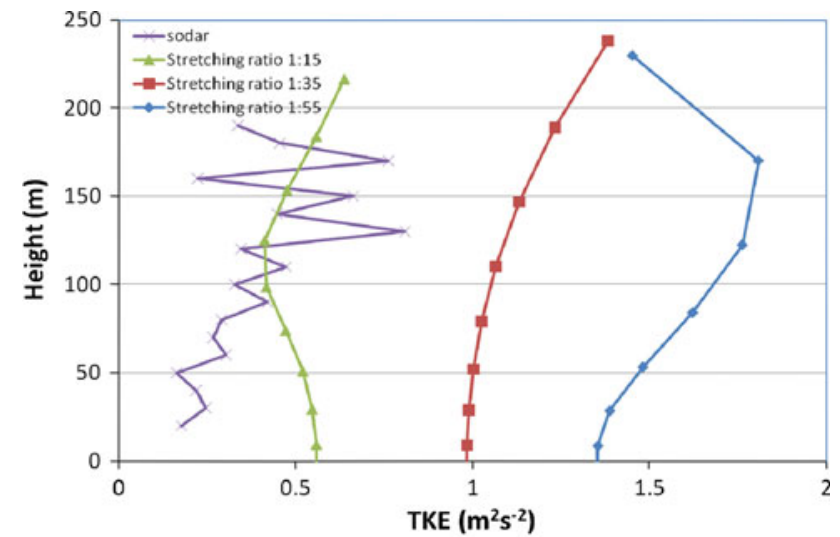

(a)

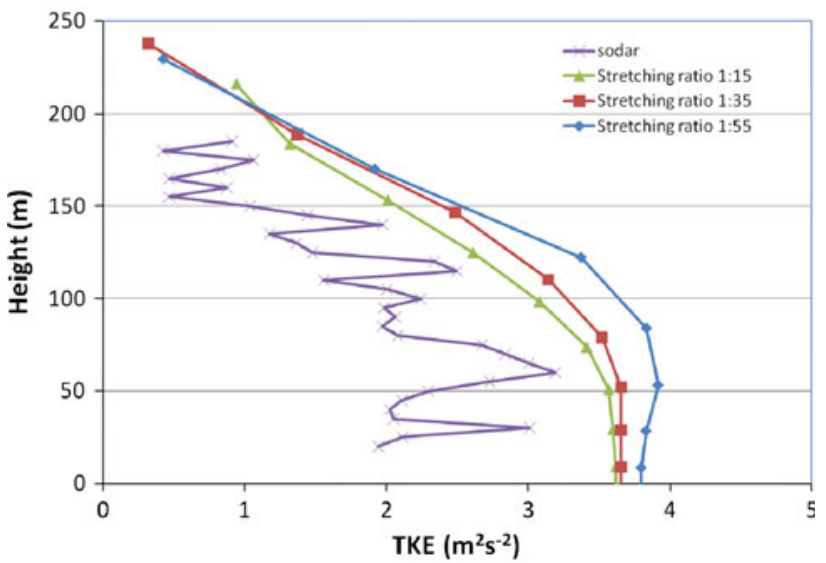

(b)

Fig. 16 TKE profile measured by the sodar at shoreline anemometer site and compared with the model-simulated results: a 03 UTC, 8 February 2010, and b 07 UTC, 5 March 2010

double counting of turbulence when the horizontal grid spacing is less than $\sim 1 \mathrm{~km}$. As such, it may have limitations in the application for model simulation with a horizontal resolution of $200 \mathrm{~m}$ in the innermost domain for the present study. Therefore, it is not surprising to see that the simulation results for EDR based on Mellor-Yamada (1982) scheme is not as good as the other turbulence schemes that consider 3D mixing, e.g. in the comparison with EDR profiles from radar wind profilers. Nonetheless, Mellor-Yamada (1982) scheme is found to be rather stable and, as found in the present study and in Chan (2009), appears to give a reasonable spatial distribution of EDR for terrain-disrupted airflow, though the magnitude of EDR is generally smaller in comparison with actual observations. On the other hand, for 3D mixing schemes such as Deardorff (1980) scheme and e-l scheme, the magnitude of the simulated EDR with a horizontal resolution of $200 \mathrm{~m}$ seems to be more reasonable compared with the wind profiler data. The vertical gridding has a size of several tens of metres to a couple of hundred metres, at least in the lower part of the boundary layer, and such a size of the 
vertical grids is comparable with the horizontal resolution. As such, the 3D mixing schemes work better in simulating the magnitude of turbulence intensity, as expected. However, these schemes are less stable and, particularly for the new e-1 scheme, simulation may blow up for a forecasting period of half an hour to an hour in strong wind situation, e.g. in association with tropical cyclones. The stability of the scheme would need to be taken into account if day-today forecasting of terrain-induced turbulence is to be attempted, such as in aviation applications.

Moreover, the present paper tries to address a number of issues of model simulation of turbulence intensity for aviation applications as brought up in the previous paper (Chan 2009). Case studies are considered for this purpose. Based on the results of limited number of cases, it has been shown that:

1. The choice of the vertical grid (in the case of RAMS, the choice of the stretching ratio) has an impact on the simulation of $\mathrm{EDR}^{1 / 3}$. Though the horizontal distribution of turbulence intensity does not change significantly, the different vertical gridding could affect the forecast magnitude of $\mathrm{EDR}^{1 / 3}$, and the selection made so far (stretching ratio of 1.15) appears to be a reasonable value in comparison with the actual $\mathrm{EDR}^{1 / 3}$ data.

2. Apart from moderate and severe turbulence cases, RAMS seems to have the capability to handle light turbulence situation as well. There does not appear to be over-forecast problem as demonstrated in a light turbulence case.

3. Based on results of limited case studies, the vertical TKE profile in the first $200 \mathrm{~m}$ or so above ground appears to be simulated well by the model, particularly for heights above $100 \mathrm{~m}$, using a vertical gridding with a stretching ratio of 1.15 . This provides further support that this choice of the stretching ratio is reasonable.

\section{References}

Chan PW (2007) Terrain-disrupted airflow over the Hong Kong International Airport (HKIA) in the southwest monsoon. In: 29th international conference on alpine meteorology, Chambéry, France, 4-8 June 2007

Chan PW (2009) Atmospheric turbulence in complex terrain: verifying numerical model results with observations by remote-sensing instruments. Meteorol Atmos Phys 103:145-157

Chan PW, Cheung TC (2009) Microscale simulation of terraindisrupted airflow around the Hong Kong International Airport (HKIA) - comparison of results between numerical models. In: 10th annual WRF users' workshop, Boulder, CO, USA, 23-26 June 2009

Chan PW, Shao AM (2007) Depiction of complex airflow near Hong Kong International Airport using a Doppler LIDAR with a twodimensional wind retrieval technique. Meteorol Zeitschrift NF 16:491-504

Cotton WR et al (2003) RAMS 2001: current status and future directions. Meteorol Atmos Phys 82:5-29

Deardorff JW (1980) Stratocumulus-capped mixed layers derived from a three-dimensional model. Bound Layer Meteorol 18:495-527

Mellor GL, Yamada T (1982) Development of a turbulence closure model for geophysical fluid problems. Rev Geophys Space Phys $20: 851-875$

Morse CS, Goodrich RK, Cornman LB (2002) The NIMA method for improved moment estimation from Doppler spectra. J Atmos Ocean Technol 19:274-295

Shun CM, Chan PW (2007) Applications of an infrared Doppler LIDAR in detection of windshear. J Atmos Ocean Technol 25:637-655

Shun CM, Johnson DB (1995) Implementation of a terminal doppler weather radar for the new Hong Kong International Airport at Chek Lap Kok. In: Preprints, 6th conf. on aviation weather systems, Dallas, TX, Am Meteorol Soc, pp 530-534

Trini Castelli S, Ferrero E, Anfossi D (2001) Turbulence closure in neutral boundary layer over complex terrain. Bound Layer Meteorol 100:405-419

Trini Castelli S, Ferrero E, Anfossi D, Ohba R (2005) Turbulence closure models and their application in RAMS. Environ Fluid Mech 5:169-192

Xu D, Taylor PA (1997) On turbulence closure constants for atmospheric boundary-layer modelling: neutral stratification. Bound Layer Meteorol 84:267-287
Acknowledgments The author would like to thank Dr. Silvia Trini Castelli for useful discussions about the e-1 turbulence parameterization scheme. The author is also grateful to the comments provided by the anonymous reviewers.

Open Access This article is distributed under the terms of the Creative Commons Attribution Noncommercial License which permits any noncommercial use, distribution, and reproduction in any medium, provided the original author(s) and source are credited. 